\title{
BREWING UP BRAND LOYALTY: THE RHETORICAL CONSTRUCTION OF THE STARBUCKS REWARDS USER INTERFACE AND HOW CONSUMER BEHAVIOUR IS INFLUENCED THROUGH GAMIFICATION AND VISUAL TROPES
}

\author{
EMILY COLLINS \\ Dr. Jessica Mudry \\ The Major Research Paper is submitted \\ in partial fulfillment of the requirements for the degree of Master of Professional \\ Communication
}

\author{
Ryerson University \\ Toronto, Ontario, Canada
}

August 31, 2017 


\section{AUTHOR'S DECLARATION FOR ELECTRONIC SUBMISSION OF A MAJOR RESEARCH PAPER}

I hereby declare that I am the sole author of this Major Research Paper and the accompanying Research Poster. This is a true copy of the MRP and the research poster, including any required final revisions, as accepted by my examiners.

I authorize Ryerson University to lend this major research paper and/or poster to other institutions or individuals for the purpose of scholarly research.

I further authorize Ryerson University to reproduce this MRP and/or poster by photocopying or by other means, in total or in part, at the request of other institutions or individuals for the purpose of scholarly research.

I understand that my MRP and/or my MRP research poster may be made electronically available to the public. 


\title{
BREWING UP BRAND LOYALTY: THE RHETORICAL CONSTRUCTION OF THE STARBUCKS REWARDS USER INTERFACE AND HOW CONSUMER BEHAVIOUR IS INFLUENCED THROUGH GAMIFICATION AND VISUAL TROPES
}

\author{
Emily Collins \\ Master of Professional Communication \\ Ryerson University, 2017
}

\begin{abstract}
Today, in the absence of a company's product or service offering, a mobile-based loyalty application can be used as a non-transactional mechanism to shape consumer behavior. This Major Research Paper takes a look into the Starbucks Rewards loyalty program platform, both from a mobile application as well as a desktop website perspective, to understand how Starbucks generates customer loyalty in the multi-billion-dollar coffee market through the application of game elements and strategic document design within the platform's user interface.

Based on a comprehensive review of Starbucks Rewards, this project addresses the following research questions: 1) In the development of a loyalty application, has Starbucks employed elements that address a consumer's behavioural motivations for autonomy, competence and relation? and 2) Within the scope of gamification and document design, how are the rhetorical appeals of ethos, pathos and logos employed in the user interface visuals of the Starbucks Rewards app and website?

Starbucks has carefully employed principles of design within loyalty marketing efforts to manipulate the communicative intent of visualizations, capitalizing on the human mind in favour of company objectives.
\end{abstract}




\section{ACKNOWLEDGEMENTS}

This Major Research Paper would not have been possible without the support of my supervisor, Dr. Jessica Mudry, for her mentorship throughout the last two terms. Thank you for being a continuous source of inspiration for my research goals, and consistently encouraging me to engage in new ideas. I would also like to extend thanks to my second reader, Dr. Matt Tiessen, who provided me with great guidance and insightful feedback throughout the writing process. Lastly, I would like to express gratitude to all of my classmates in the Master of Professional Communication program who undeniably contributed to a rewarding and memorable graduate school experience. 


\section{TABLE OF CONTENTS}

1.0 INTRODUCTION …….................................................................................................................................1

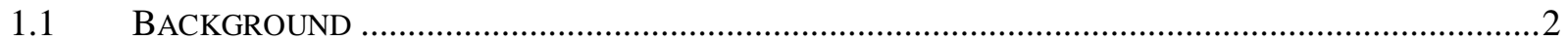

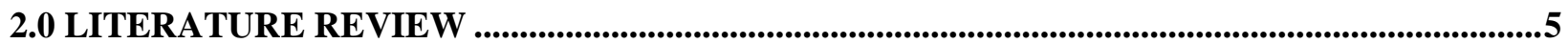

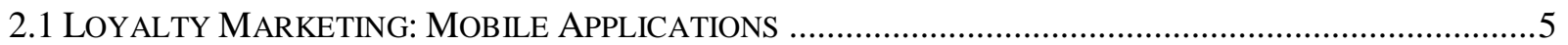

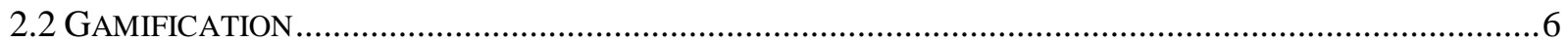

2.3 Marketing and the MarketPlace, A MarXist PersPective............................................... 10

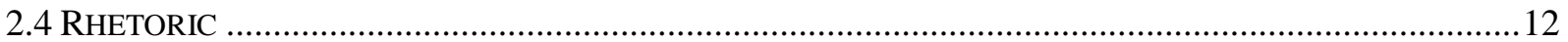

2.4.2 Document Design as a Form of Persuasion ...................................................................... 13

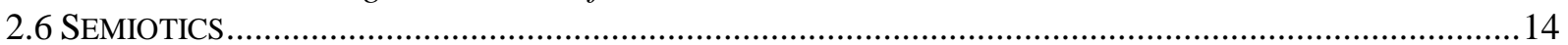

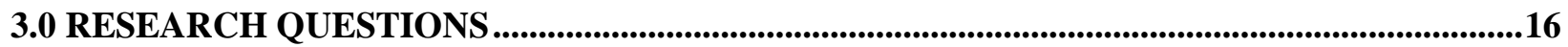

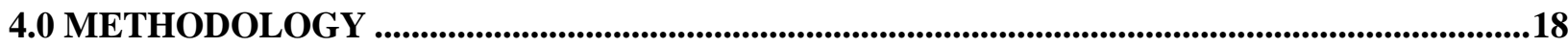

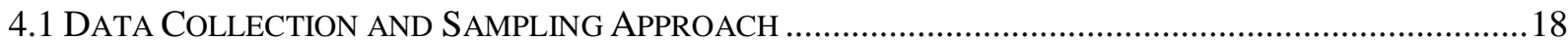

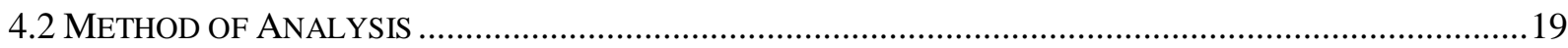

5.0 ANALYSIS

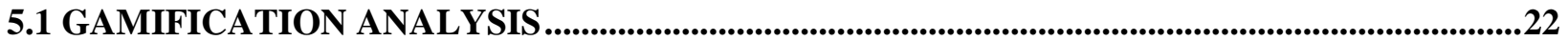

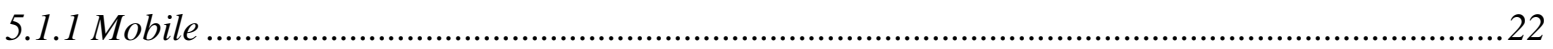

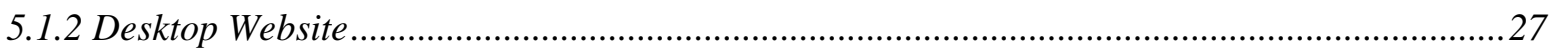

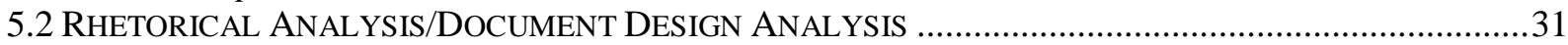

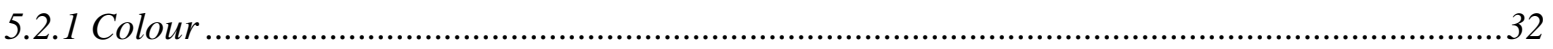

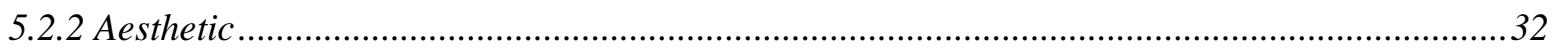

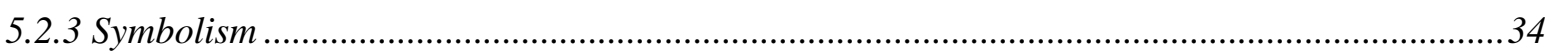

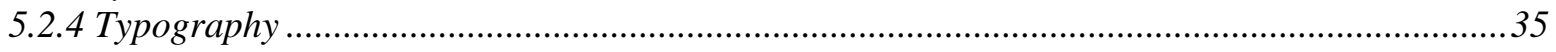

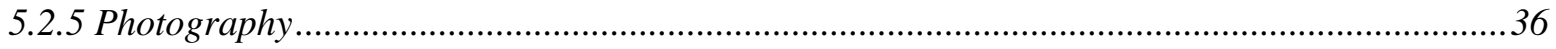

7.0 CONCLUSIONS

8.0 LIMITATIONS AND CONSIDERATIONS FOR FUTURE RESEARCH..................................45

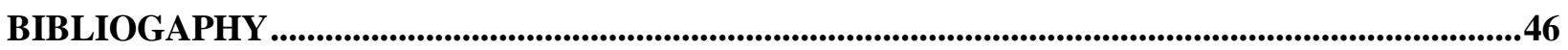

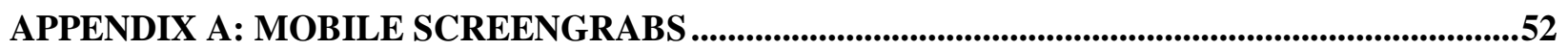

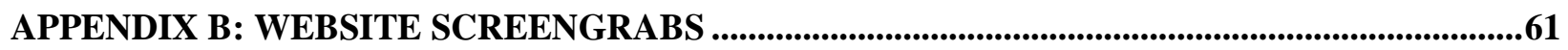

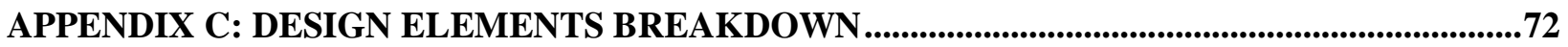




\section{LIST OF FIGURES}

Figure 1: Examples of the use of animation from mobile app 22

Figure 2: App purchase history $\quad 24$

Figure 3: The use of notification controls, menu options, maps and legends 24

Figure 4: Integration of social networks 25

Figure 5: Bonus Star Bingo, Desktop Website $\quad 28$

Figure 6: Profile and Account Information 30

Figure 7: Examples of typical typography used on app and website 33

Figure 8: Examples of the use of professional photography 35 


\subsection{Introduction}

In the modern marketing environment, the investigation into brand loyalty has become increasingly essential, especially in the digital age (Latif et al., 2014). When it comes to building a digital rewards program, it is imperative that marketing practitioners have a comprehensive understanding of the human consumption processes that take place while an individual interacts with a digital user interface.

Since practices of digital culture and of interactivity have been introduced to consumers, gamification marketing has become an important manifestation of digital technology (Harwood \& Gary, 2015). From another communication standpoint, graphic design elements have the ability to elicit certain behavioural responses in humans. For Mittal (1988), the consumer is an information-processing system. Every design element, from colour, to shape, to scale and typography, has a place in visually communicating meaning to a consumer. Furthermore, 95 per cent of all a human's cognition occurs in the subconscious mind, and thus understanding deeper levels of consumer thinking has tremendous value for designing marketing material (Mahoney, 2003).

This Major Research Paper (MRP) examines reward program design and the application of game elements and visual rhetoric in online loyalty marketing. The paper explores what makes gamification and document design, as marketing techniques, appeal to audiences and ultimately drive consumer engagement. I have chosen to focus my research on the Starbucks Rewards program in particular. This loyalty program is offered on a mobile app whereby customers can 
collect virtual points - or "stars" - with the goal of having these points eventually translate into free merchandise. According to "My Starbucks Rewards" (n.d.), at the end of the company's first fiscal quarter of 2012, Starbucks calculated that one-in-four customers used the loyalty program when making a purchase. Much of my interest for researching mobile applications and their calculated interface design was fostered throughout my Master's degree in class discussions revolving around technology's perpetual impact on society. Given my continued fascination with how subconscious marketing design manipulates the consumer, along with this generation's obsession with Starbucks, I have chosen to use Starbucks Rewards as a case study for this MRP.

\subsection{Background}

Starbucks Rewards is a loyalty program that combines interactive elements and a streamlined payment process with tangible rewards. To receive loyalty program benefits, an individual must

first enrol in Starbucks Rewards by creating an account and activating a Starbucks card linked to the account. This card has similar functions to a gift card or credit note, and multiple cards can be placed on one user's account.

The program, which initially launched in 2009, uses a mobile application whereby customers collect points and are offered rewards. The virtual points are collected until designated levels are reached, at which point the levels eventually translate into free merchandise and other in-store perks (“My Starbucks Rewards”, n.d.). Since the program’s initial launch, Starbucks become well known as a company that strategically aligns itself with digital innovation to improve the customer experience.

As the company becomes increasingly globalized with 25,000 stores across the globe, Starbucks 
is faced with the conflict of potentially losing its identity, leading customers to forget about its "high-quality" coffee (Roderick, 2017). Local, independent coffee shops are slowly threatening to steal Starbucks' consumers away by providing the same type of experience that Starbucks has long been famous for. To combat this threat over recent years, the company has increased its focus on tech (Roderick, 2017). As stated by Roderick (2017), first, the Mobile Order \& Pay application rolled out across the U.S. in 2015, whereby customers could pre-order their food and beverage to cut down on queuing time. Second, to help with the challenge of keeping customers engaged, Starbucks has used gamification as a strategy to increase return visits, and has been successful in doing so. In particular, the company has recently been pushing a game called Star Dash, which is a gamification of the loyalty program and has been highly successful (Roderick. 2017).

In its loyalty marketing efforts, Starbucks uses progress bars, leveling and rewards as motivators. Each purchase a customer makes using the mobile app, depending on the amount spent, is rewarded with a specific number of points, or "stars". When customers reach certain levels with their stars, they are awarded with a variety of different incentives. As an example, at the first level - or the "Green" Level - customers are allowed free in-store refills on coffee and tea. When an individual reaches the "Gold" level, they are sent a personalized Gold member Starbucks card as a material token of appreciation that also acts as an indication of status ("My Starbucks Rewards", n.d.). Much of the current literature that exists surrounding loyalty marketing examines consumer behaviour and the concept of gamifying the buying process, as Starbucks does with the exchange of stars for coffee. 
As a broad variety of disciplines lend themselves to relevant communication theory, many theoretical areas will serve as lenses for analyzing loyalty-building efforts in this research paper: gamification, visual rhetoric and semiotics. The MRP will aim to discover parallels between theoretical positions and the associated application, and proposes to analyze the visual elements of a mobile gamification application.

In recent years, there has been a growing trend toward incorporating gamification in marketing to drive consumer engagement. One of this project's goals is to understand how gamification has the ability to cater to consumers' intrinsic and extrinsic motivators (Conway \& Garay, 2014). It will also explore current research that exists on the concept of gamifying the "experience of buying”, which Starbucks facilitates with the exchange of virtual stars for tangible goods. Today's digital media environment has the ability to facilitate exchange and consumption at any time or place and the idea "the medium is the marketplace" has thus become legitimate (Kirkpatrick et al., 2016; McGuigan \& Murdock, 2015).

Finally, the inherent use of visual rhetoric in marketing will be investigated. This will be done by the unpacking of document design in the Starbucks Rewards app and website user interface to understand the psychology of persuasion, and how it is embodied in the communication used in advertising and digital technology. 


\subsection{Literature Review}

This literature review will explore research on the topics of gamification, visual rhetoric and document design, and pull insight from important authors in each field. It will compare similarities within the existing literature and look for opportunities where the research could benefit from further exploration. The review uses relevant Consumer Behaviour, Sociology, Psychology, Business and Communication theories and ideas as a basis for analyzing what constitutes the ideal design of a digital loyalty program's platform. The aim here is to help marketing managers and mobile app designers in the future to develop more robust and reliable loyalty program interface designs. Little research has focused on the potential to encourage consumer loyalty through both design variables and gamification elements within the construction of a loyalty rewards program. This literature review provides theoretical insight into why design, in the form of visual tropes and game elements, might be used to trigger specific behaviours in consumers of digital media.

\subsection{Loyalty Marketing: Mobile Applications}

Customer adoption is a struggle for any new mobile app; brands must first compel customers to download the app, and then actually use it. According to Zack, a mere three days after the installation of an application, 77 percent of customers will never use the app a single additional time (2017). This means that it is vital for brands to motivate customers to use the app by providing a constant stream of exclusive offers (Zack, 2017).

Work done by Latif et al. (2014) presents a conceptual framework for building loyalty based on a 
review of existing literatures. As explained by Latif et al. (2014), brand loyalty can be viewed as a creative mind set, on behalf of a brand, that leads to the continuous repurchasing of a brand over time. This brand loyalty framework is based on four elements: familiarity of the brand, satisfaction of the customer of the brand, trust of the brand and attitudinal loyalty of the brand. Familiarity is customers' cognitive representations of experiences related to a brand, and existing knowledge about a brand. Satisfaction refers to positive consumption experience, so a level of emotional evaluation comes into play. Trust requires commitment and cooperation, and is a major variable in the discussion of relationship marketing. This framework will serve as a basis to understand whether the visual design of Starbucks Rewards caters to the four elements required to build brand loyalty. Attitudinal loyalty to a brand can be measured by a customer's intention to recommend and/or repurchase, low intention of switching to competitors' brands, attachment, and willingness to pay a price premium. (Latif et al., 2014). These four elements are crucial to consider when building a customer loyalty platform (Latif et al., 2014).

\subsection{Gamification}

The concept of gamification has been popular in research due to its development in business applications in recent years. First, it is important to clarify and define gamification as it is utilized frequently throughout this paper's analysis and the meaning of the term can differ depending on its context. Sailer (2017) states that the term emerged in the early 2000s and described it as the use of game elements in typically non-game situations. Additionally, as put by The American Marketing Association, gamification describes the application of psychological and sociological factors that motivate intense game play to consumer measurement, and is now recognized as a popular disruptive technology trend. As put by Dale, an important contributor to 
research in gamification in recent years, gamification seeks to apply fun and challenge pleasurable aspects of games - to real-life business situations (2014).

Hofacker et al. (2016) create an interesting conversation around gamification use in mobile devices. Traditionally, it is up to customers to enter a retail space, but cell phones have allowed retailers to invert this paradigm by coming into a buyer's personal environment. They note that symbolic economies, brought about by game tactics, are now replacing the real economy in many business applications. Hofacker et al. (2016) recognize the Elemental Tetrad Model, a framework devised by Shell (2008), which states that in order for player engagement to occur in a game, four elements must be present: story, mechanics, aesthetics and technology. It can be argued that these elements play a role in creating rhetoric, which is discussed later in this literature review. Hofacker et al. (2016) bring important ideas to the concept of gamification, and build on the fact that to promote consumer loyalty, a game must have an effective ecosystem.

It is necessary to review literature that surrounds gamification due to the marketing technique's ubiquitous nature in today's strategic communications, and its ability to connect with consumers outside of a typical purchase interaction. Gamification techniques have helped encourage customer engagement and produce greater monetary results, and thus the implementation of these business platforms has gained acceptance (Conaway \& Garay, 2014). In fact, participation in digital games has become so popular that as of 2013, participation rates were found to be at 50 per cent, 46 per cent and 43 per cent for Americans, British and Germans, respectively (Harwood \& Garry, 2015). 
As explained by Harwood and Garry (2015), relevant contributors to the field of marketing gamification, gamification's primary goal is to immerse customers into an experience where they will feel emotions and exhibit behaviour similar to other typical online games and virtual engagement techniques. What is said to be different in loyalty programming, however, is that a component of competition exists for the consumer as a challenger motivator, ultimately eliciting both emotional and behavioural responses around a brand (2015).

Research completed by Harwood and Garry (2015) discusses consumer engagement in depth, and how firms value it as a highly desirable need in order to be profitable. This is because, in the absence of the firm's service or product offering, companies can use various non-transactional mechanisms to shape and control consumer behaviour. These mechanisms may provoke different behavioural responses both from a customer-to-customer and customer-to-firm perspective. To be more precise, examples included in research are: customers assisting other customers, wordof-mouth marketing, delivering feedback to the company, and better compliance with company's general procedures (Harwood \& Garry, 2015). Harwood and Garry empirically generated insights into gamification using a mixed-methods design to address research questions. This design incorporated netnography and participant observation, with Samsung Nation as a case study.

Harwood and Garry's 2015 research states that a company can be positively affected when a gamified brand experience is used in communications with consumers. The idea here is that after an enjoyable interactive experience, perhaps a consumer will undergo positive cognitive, emotional and behavioural outcomes when exposed to the brand due to the establishment of a 
positive pre-disposition. Or, as put by Harwood and Garry (2015), "within a branding context, there is an imposition of game mechanics on to brand content" (p. 535). This is said to create a "gamification loop", which intends to promote a repetitive behavioural pattern (Harwood \& Garry, 2015).

Like Harwood and Garry (2015), Conaway and Garay's 2014 work in gamification recognizes game-based marketing as an exploding trend. This research aimed to quantify the concept of gamification through using a survey to identify both customer and management perspectives on gamification platforms, which derived important information surrounding features that attract consumers. These 4 features include progress paths, feedback and reward, social connection, and attractiveness of an enterprise's site (Conaway \& Garay, 2014). The attractiveness of a user interface will be linked to further research on visual rhetoric theory, discussed later in the literature review.

After a review of current literature, it is apparent that marketing practitioners and researchers alike do not have obvious reasoning for the failure of many loyalty programs. As outlined by McGuigan and Murdock's “The Medium is the Marketplace: Digital Systems and the Intensification of Consumption" and argued by Marx, two important developments are needed for sufficient profit generation: "the production of new consumption" (p. 721) and the acceleration and extension of circulation (McGuigan \& Murdock, 2015). When combining the concept of ubiquitous media with theories surrounding gamification, we see a parallel in Golumbia's (2009) idea that there are "extensions of physical economies into our own ideologies imaginaries" (p. 196). 
Sailer describes game elements as the basic building blocks of gamification applications. Some of these game elements include, but are not limited to, points, badges, leaderboards, meaningful stories, avatars and profiles (2017). These types of game design elements can purposefully address motivational mechanisms, and from a theoretical perspective specific psychological needs can be matched to specific design game elements. These psychological needs include the need for autonomy, the need for competence, and the need for relation or social relatedness (Sailer, 2017). As per Aparicio (2012), examples of elements that address each need are as follows: (1) Autonomy: profiles, avatars, macros, configurable interface, alternative activities, privacy control, notification control. (2) Competence: positive feedback, optimal challenge, progressive information, intuitive controls, points, levels, leaderboards. (3) Relation: groups, messages, blogs, connection to social networks, chat.

In recent years, many academics have been critical of gamification as a marketing tool, as there is not any direct evidence that implies that behavioural loyalty, or repeat purchase, is a result of game mechanics, regardless of efforts made by marketers to drive consumer engagement. In addition, as put by Harwood and Garry, gamification is directed by the assumption that contemporary technologies will converge with "informed, connected, empowered and active consumers" (2015, p. 533).

\subsection{Marketing and the Marketplace, A Marxist Perspective}

The next area of research seeks to understand the collaboration between marketing and the marketplace and how dynamics of capitalism have contributed to mobile technology; more specifically, for the use of customer engagement. Has Starbucks Rewards been designed with the 
future of capitalism in mind, along with the expansion of the online marketplace in recent years? Current literature by Kirkpatrick et al., McGuigan and Murdock, and Andrejevic aid in the understanding of the traditional consumption system and how might it affect contemporary technology trends.

Consumption continues to be ever-evolving; engaging and entertaining experiences are now considered to be the status quo (Kirkpatrick et al., 2016). McGuigan and Murdock’s 2015 commentary analyze how the consumer system has been organized around the progressive integration of marketing as a method to provoke demand and desire in the promotion of products. This system is consistent with contemporary capitalism, seeing marketplaces as grounds for interaction with goods in the material worlds, and payment structures built on credit. Andrejevic agrees with this in explaining that with connectivity to today's media being ubiquitous, mobile devices are seldom exclusively messaging platforms, as they also act as virtual storefronts for which the shopping experience is available anywhere, anytime (2007). McGuigan and Murdock relate frictionless pay systems brought about by mobile applications to the idea of an "always-on consumer" characterized by a constant "shopping state of mind" (McGuigan \& Murdock, 2015, p. 722). Similar to McGuigan and Murdock (2015), Kirkpatrick et al. (2016) analyze the Marxist perspective on digital marketing, but focus back onto the idea of game-based mechanics. The pressures brought about by commodification drive marketing practitioners to find techniques in which a game can sustain player interest. These insights, along with other contributors to contemporary technology research, offer an essential departure point for critical analysis on Starbucks Rewards.

While an abundance of literature exists on mobile marketing and gamification, there is an 
evident gap in research that could help mobile app designers build a loyalty program to attract consumers through both the application of gamification and visual design elements. Kirkpatrick et al., previously mentioned scholars in gamification research, discuss a relevant Marxist perspective that explores aesthetics: the computer game has an important position whereby it is seen as a modern medium and art form (2016).

\subsection{Rhetoric}

Simply put, rhetoric can be defined as "formal strategies that make communication effective" (Amare \& Manning, 2007, p. 58) As explained by Leach (2000), rhetoric structures society’s way of thinking through the power of discourse and language. Rhetoric is catered to a discrete audience, who is persuaded by given arguments and, classically, show some change in opinion or behaviour (Leach, 2000). Since marketing practitioners can shift an audience's attitudes and feelings through rhetorical figures, they have the power to influence the buyer's decisions and actions. Thus, the application of rhetoric is widely used in visual design as a way to create content that is both engaging and memorable to a consumer.

Winn and Beck state that visual design on websites possess rhetorical appeal, and that web designers should understand this in order to build a platform whereby consumers will be persuaded to buy (2002). There are three elements that exist within the design elements on an ecommerce platform, per Winn and Beck, that carry out the rhetorical function of persuasion (2002). The elements are ethos, pathos and logos, and serve as a framework for understanding a detailed classification of the means of persuasion. The combination of these three appeals are said to be considered factors that heighten the probability of a consumer making a purchase on an e-commerce website (Winn \& Beck, 2002). The first, ethos, refers to the appeal to credibility. 
On an e-commerce website, design that promotes recognizability, compatibility, assurance and reliability establishes trust and credibility for the customer; this will establish ethos. The emotional appeal, pathos, can be achieved on a website through attributes that promote tangibility, playfulness and empathy. Lastly, logos, or the appeal to logic, depends on salient factors such as price, product information, variety and effort. These factors should optimize overall web experience by increasing a consumer's ease of navigation and decreasing a customer's mental effort while interacting with the medium (Winn \& Beck, 2002).

\subsubsection{Document Design as a Form of Persuasion}

Another area of research that will help lead my analysis in understanding strategic marketing within the context of Starbucks will be document design. Interpretation of visuals happens so fast that oftentimes readers are unaware of the complex processes that are involved (Schriver, 1997). Schriver (1997) views document design as a fusion between art and science in which texts are created to bring prose, graphics and typography together for the purpose of information, instruction or persuasion. Schriver explains that good document design has an influence on a person's perception of goods and services (1997). Well-chosen typography must have rhetorical appropriateness, which revolves around "the relationship between the typeface, the purpose of the document, its genre, the situation, and the audience's needs, desires, and purposes" (Schriver, 1997, p. 283). Likewise, information hierarchy serves as a rhetorical function as it guides a viewer through complex content using the strategic placement of information based on relative importance (Bowers, 2008). This allows the viewer to quickly understand the content being display and relate it to their own needs. For this reason, clear information hierarchy in a document can improve the legibility of that document (Bowers, 2008). 


\subsection{Semiotics}

As explained by Oswald (2012), semiotics is a discipline within social science that approaches semiosis, the active production of meaning, in a cultural perspective. This discipline can be used to interpret marketing strategy as it approaches consumer behaviour and culture as systems of symbolic rituals and signs (Oswald, 2012). C.S. Peirce, communication theorist and semiotician, shows us a three-part theory of rhetoric that broadens the concept of the sign and takes into consideration an audience's emotional, practical and intellectual experiences (Amare and Manning, 2007). Amare and Manning present this theory as one that is organized around three primary communication goals, offering an integrated semiotic framework encompassing both text and graphics within a common visual-language system. The three rhetorical communication goals are 1) to decorate, 2) to indicate, and 3) to inform (Amare and Manning, 2007). Peirce's Firstness, to decorate, creates the overall feeling of a document for an audience. This includes aspects such as colour, font shapes, borders, and so on; they are feeling-generating forms and can be referred to as decoratives. Peirce's Secondness is to indicate, and includes text and graphics that provoke an audience to action, such as page tabs that can be turned, web links that can be clicked, etc. These are referred to as indicatives, and are action-provoking forms of text. Peirce's Thirdness is to inform, in the way of idea-promotion forms called informatives. Examples of informatives include stories, sales pitches, explanations, and so on. They act to further the understanding of an audience (Amare and Manning, 2007). These concepts will help guide my analysis in identifying visuals, symbols and other metaphorical artifacts, and how might they act as perceptual cues to a viewer.

This paper seeks to gain a greater understanding of many neglected, yet important, attributes of 
loyalty programs. These neglected areas have the potential to be rooted in strategic rhetoric, and include how elements such as document design of a user interface, aesthetics, and game-based design elements work together to encourage consumers to interact with a brand. 


\subsection{Research Questions}

Few studies have focused on the potential to encourage consumer loyalty through both design variables and gamification elements within the design of a rewards program. Starbucks Rewards is a relatively well-established program with regards to consumer loyalty in recent years. Thus, I will use this platform as a case study for understanding how design, in the form of visual tropes and game elements, is used to strategically trigger certain behaviours in program users. The analysis of this MRP will therefore aim to address the following research questions:

RQ1: In the development of a loyalty application, has Starbucks employed elements that address a consumer's behavioural motivations for autonomy, competence and relation? Here, a basic assumption is that certain game design elements can be used to address motivational mechanisms, which include 1) the need for autonomy, 2) the need for competence and 3) the need for relation (Sailer, 2017). This question seeks to explore the power of gaming and its known ability to control consumer behaviour, as informed by theory. It is known that marketing practitioners encourage the incorporation of game mechanics in marketing (Conaway $\&$ Garay, 2014), and this question will work to further investigate how non-game contexts, such as loyalty marketing apps, can be modified to satisfy certain human needs, thereby motivating consumers to perpetuate the use of a program.

RQ2: Within the scope of gamification and document design, how are the rhetorical appeals of ethos, pathos and logos employed in the user interface visuals of the Starbucks Rewards app and website?

Like the previous question, it is understood that the design of a user interface can be catered to 
control human motivation and performance in regard to a given activity. To answer RQ2, this project will develop a rhetorical analysis of visuals used in the Starbucks Rewards desktop website and mobile application. Since a loyalty program is a form of marketing material, it is assumed rhetorical strategies should be already adopted within the existing document design of the user interface, and that they can be identified as occasions of ethos, pathos and logos. 


\subsection{Methodology}

\subsection{Data Collection and Sampling Approach}

For this MRP, all data was collected from Starbucks' online media. More specifically, I have examined Starbucks' loyalty marketing efforts from the company's desktop website and mobile application. The content analyzed contains visual utterances, and their stylistic features have been studied in depth. Material from both Canadian and American versions of the app were collected.

In order to ensure the quality of the data collection procedure for qualitative research, per Bryman and Bell (2016), I have considered the data by examining the context of the images within the Starbucks media (their "natural setting", p. 408), and noting the textual or physical characteristics in situ. The data set was obtained from a convenience sampling process, as there was a limited number of pages and screenshots appropriate for analysis. My intention was to capture data within its typical setting so as to best understand the consumer's authentic viewing experience. Clippings from the website and app were taken using a screenshot function each day, between March 26, 2017 and May 7, 2017; this six-week window ensured I covered multiple promotional campaigns and that there was enough data to examine.

The type of data collected was predominantly guided by my research questions and by themes that emerged from my literature review to ensure the type of visuals I analyzed best suited to the paper's objectives. The data was analyzed by category based on whether the material was static or temporary (content type), and whether it was retrieved from either mobile or desktop (platform). These categories were used simply to keep screenshots organized. They are described 
below.

\begin{tabular}{|l|l|}
\hline Content Type & Description \\
\hline Static & $\begin{array}{l}\text { Content is meant to be fixed for some time; the } \\
\text { week-to-week look and feel does not change }\end{array}$ \\
\hline Temporary & $\begin{array}{l}\text { Content is only available for consumption for a } \\
\text { short duration of time; this includes daily, } \\
\text { weekly, or monthly promotions }\end{array}$ \\
\hline Platform & \\
\hline Desktop & $\begin{array}{l}\text { Content retrieved from a desktop or laptop } \\
\text { computer; from website www.starbucks.ca or } \\
\text { www.starbuck.com }\end{array}$ \\
\hline Mobile & $\begin{array}{l}\text { Content retrieved from the Starbucks' Rewards } \\
\text { Apple smartphone application }\end{array}$ \\
\hline
\end{tabular}

All data collected was related specifically to Starbucks' loyalty program, Starbucks Rewards.

The exploration of gamification models and rhetorical structures benefited from me manually pulling relevant cultural artefacts from Starbucks' media rather than using a tool to scrape website data.

\subsection{Method of Analysis}

The research method used for this Major Research Paper will be a qualitative visual content analysis. The qualitative nature of this analysis seeks to take an epistemological position, to ultimately gain a greater understanding of the social world and consumer motivators that exist within it (Bryman \& Bell, 2016). I amassed the images and words within the context of the Starbucks' loyalty program, and used a visual content analysis to identify tropes that Starbucks uses as strategic devices to encourage and persuade people to engage with the program, and perpetuate its use. 
Here, raw data was condensed to establish clear links between research objectives and findings, as I wanted to verify that these links were transparent (were able to be demonstrated to others) and were justifiable given the objectives of my research (Thomas, 2006). The outcome of this research aimed to develop contextual understanding from observation, in hopes of contributing to existing literature on loyalty marketing. As put by Pauwels (2012), "website design and layout features are essentially tools used to attract, direct and invoke the desired effect on, or response from, website visitors. However, through these choices, they also convey producer-related ideas, opinions and aspirations" (p. 255).

As explained by Bryman and Bell (2016), it is imperative that observation and interpretation be completed in a consistent manner (2015). This analysis observed collected media, systematically, to identify relevant characteristics relating to research questions. More specifically, RQ1 looked for artifacts relating to the human psychological needs for autonomy, competence and relatedness, which required an examination of game specific elements, or a gamification analysis. This is addressed in the first section of my analysis. The second half of my analysis focused on visual rhetoric and mainly looked at document design items to break down how Starbucks has incorporated forms of ethos, pathos and logos in their user interface design. This part of the analysis addressed RQ2.

The analysis process took place by assessing elements and meanings within the material to draw conclusions on emerging themes or commonalities observed. Emerging themes were developed and explored by studying the content repeatedly and keeping in mind possible meanings (Thomas, 2006). I was first required to inductively generate a list of key thematic ideas from a 
review of literature, previous research and a preliminary review of data (Gibbs, 2007).

The intended result of this series of actions, per Thomas (2006), was to develop a smaller number of summary categories that capture the key aspects of the themes identified in the raw data and, ultimately, address research questions. A content analysis was the best approach to answer the chosen research questions as my research goals sought to justify and rationalize marketing managers' specific efforts to motivate consumer behaviour and the gamified ecommerce world. The method allowed for the deconstruction of marketing efforts to understand strategies that are both conscious and intentional, and have the power to alter consumer attitudes. 


\subsection{Analysis \\ 5.1 Gamification Analysis}

\subsubsection{Mobile}

The first medium that I have analyzed is the Starbucks Rewards mobile app.

Throughout the duration of this project's data collection process, two promotional campaigns ran with temporary interactive content placed on the Starbucks app. Both promotions revolved around the anticipation of Canada's $150^{\text {th }}$ Birthday. The first, Starbucks Road Trip Morning Edition, is an instant prize game. This allowed Canadian users one "Play" on the
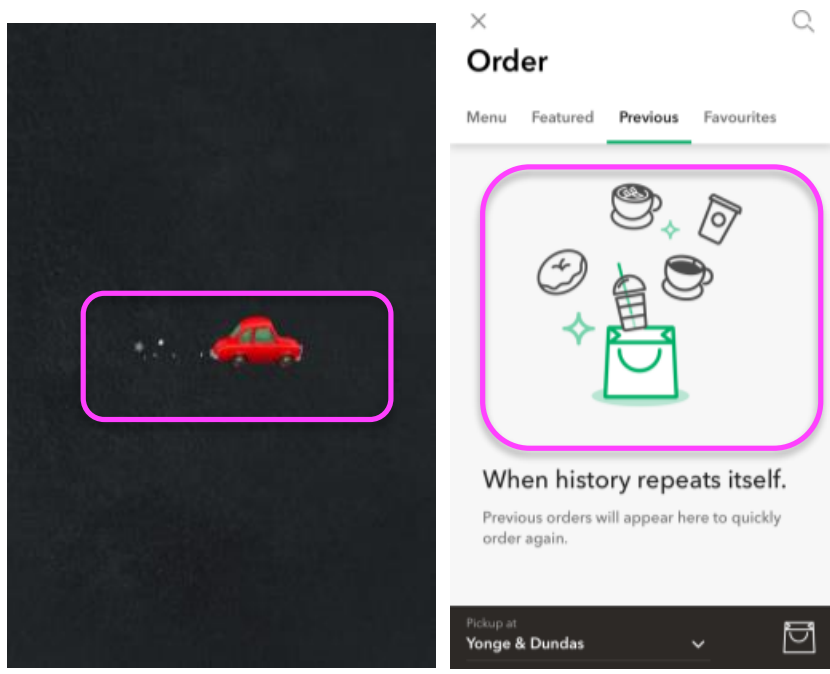

1 Animations

Figure 1: Examples of the use of animation from mobile app

app per in-store purchase for a chance to win instant prizes such as free coffee for a year, credit to loyalty cards, or bonus stars. The second, \#150PlusWishes, is a campaign that encourages consumers to share photos of their "wishes" for the future of Canada to social media, with Starbucks donating \$1 per wish to support Canadian youth in finding meaningful employment. Clippings for the design content of both promotions can be found in Appendix A of this project, along with screengrabs of the app's more stable, static content.

Characteristics of games can be used as motivational tools for consumer behaviour (Aparicio et al., 2012). A user of the Starbucks Rewards mobile app will experience small cartoon animations while navigating from screen to screen on the platform, as shown in still images in Figure 1. 
These animations are played throughout different sections of the platform, mostly in instances where a page is loading. Animations, which are considered to be series of still images recorded in various positions of incremental movement (Aparicio et al., 2012), can be used as a tool to subconsciously attract viewers' attention through motion. The use of animations (see Figure 1) in an advertising context is said to have psychological effects on a consumer that are related to high arousal levels and greater advertisement recall (Jin, 2011).

As the app is constantly changing from month to month with different promotions and campaigns, Starbucks uses instructions (see Figure 1; items labelled '1') to help people learn quicker and easier, thereby enhancing their enjoyment with the brand. Not only do instructions act as a game element, they also act as an informational piece that describe a game's purpose and objectives, with the goal of improving both the consumer's comfort and competence while playing a game. Additionally, a progress bar for virtual points is depicted in Figure 1. Progress bars are used throughout the app as a perceived indicator of filling a "bank"; they therefore cater to the psychological desire to advance or progress. Virtual points, or in this case, Starbucks "stars" are earned with each purchase and presented in numerical form alongside a progress bar in Figure 3. Like progress bars, points represent positive feedback (Mekler et al., 2017), and support the human motivation of the need for competence while playing a game. Figure 3 also portrays a game element which satisfies the need for autonomy and the need for competence, which is the display of the user's purchase history. Here, the history and display of points acts as a customized profile whereby the user can track his or her achievements and previous transactions with the company. 
The next game element that is incorporated in the

Starbucks Rewards app and is used frequently through the app's document design is leveling. Consumers see levels as elements that are associated with further performance gains. Users see game levels as perceptual cues of having reached certain goal metrics. Starbucks uses two levels to label a user's status; first, the Green Level, where users have collected between 0 and 299 stars, and second, the Gold Level, where users have collected 300 stars or more.

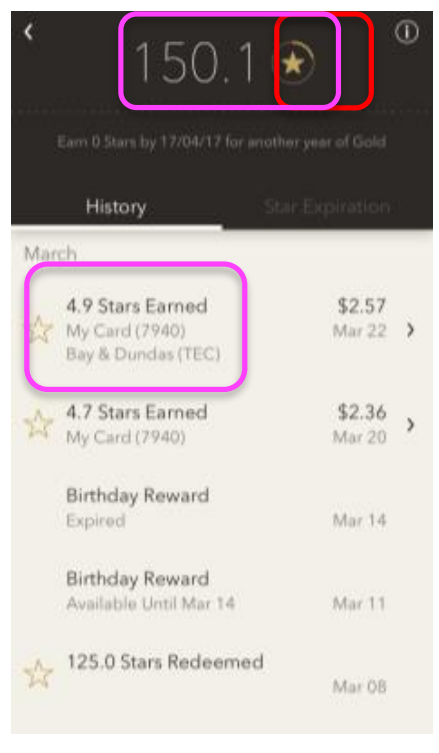

1 Points 2 Progress Bars

Figure 2: App purchase history

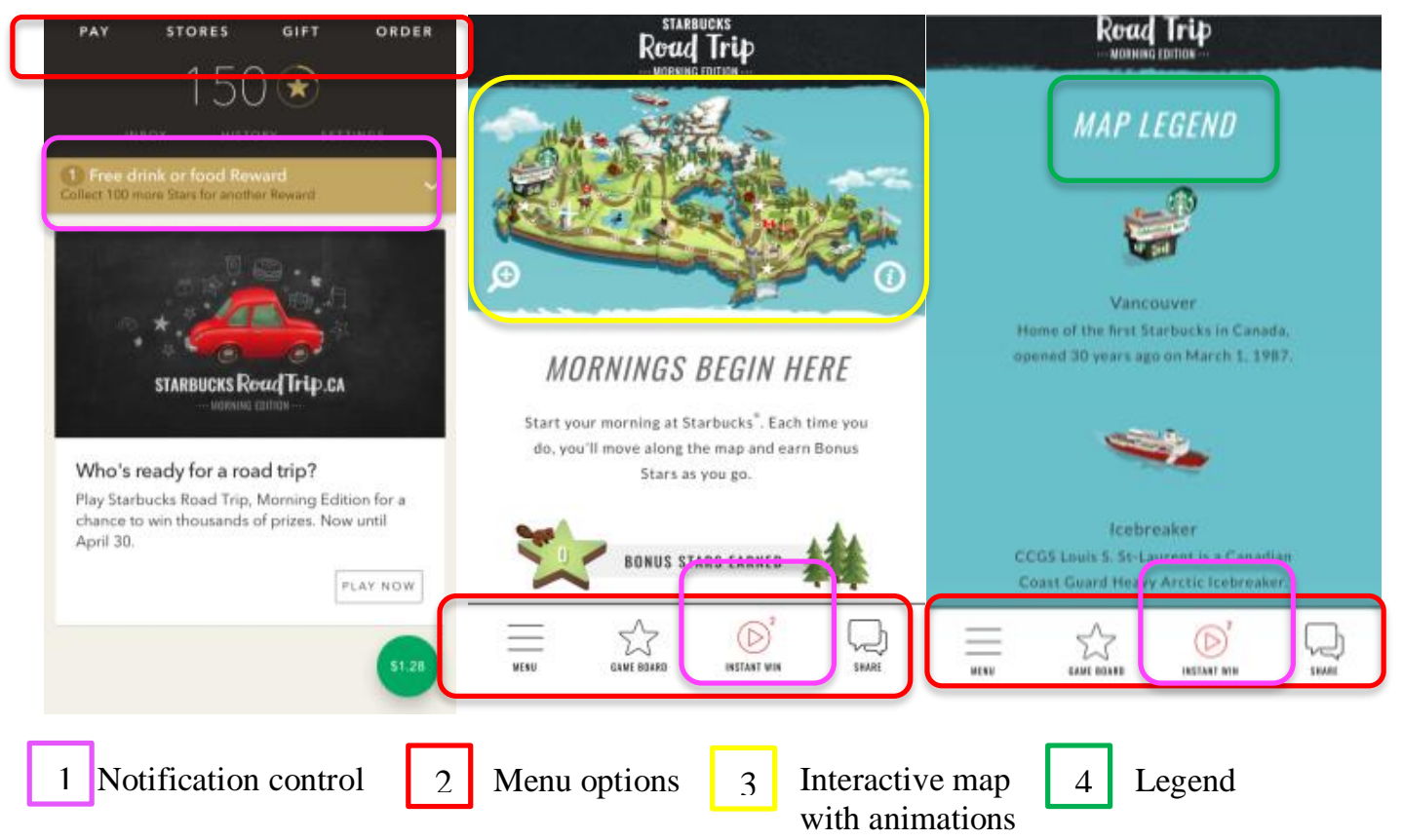

Figure 3: The use of notification controls, menu options, maps and legends

Figure 3 portrays examples where notifications, menus, interactive maps and legends are used in the mobile app. These items act as informational pieces for the viewer, and help satisfy the level 
of competence a user feels when

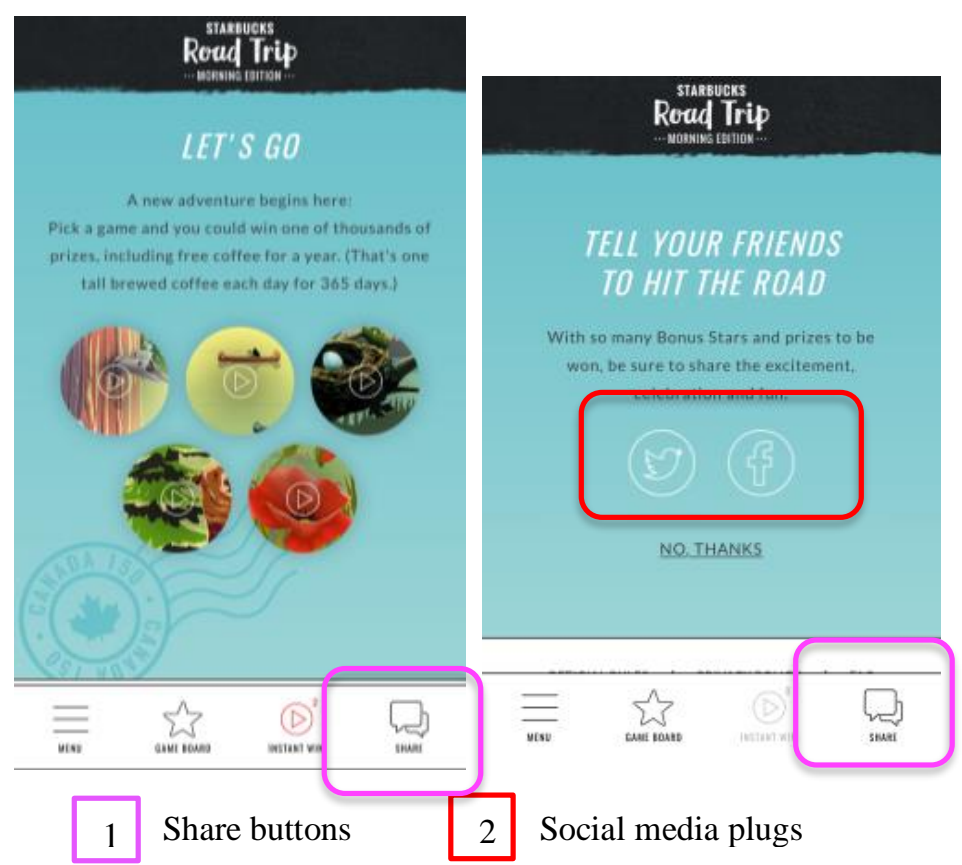

interacting with the platform. These

items improve the availability of

information on the app, and therefore

improve the user's overall

responsiveness to the app's functions.

Road maps in an app's game design

provide greater context for player; a

roadmap can act as narrative element,

identifying with the relatedness

Figure 4: Integration of social networks

motivator, and can also act as progressive information, which addresses the competence motivator.

In multiple instances, Starbucks gives the user opportunities to feel connected, whether it is a connectivity with their own peers or with the greater community. Humans are appealed by social motives, and therefore a crucial part of a digital games' playability is for users to experience game and design elements that match of the objectives of the human need for relation or relatedness. As explained by Conaway and Garay, a key element of the attraction of gamification is when a game can leverage a customer's social network and provide instant access to friends and social connections (2014). The first app element that can be said to satisfy this need is the Starbucks Card eGift function, whereby a user can send to a recipient via the app for redemption in-store. This function changes depending on the current occasion at the time (for example, Graduation and Father's Day, as shown in Appendix A.) Next, the Starbucks Rewards mobile 
app platform satisfies the human relationship need through the promotion of the \#150PlusWishes campaign as shown in Appendix A. Since the need for relatedness affects enjoyment and predicts future game play (Ryan et al., 2006), the integration of games and social networks also presents an interesting opportunity to reinforce this need (Aparacio, 2012). Throughout the mobile app's platform, app designers have established opportunities for users to share their progress and connect their rewards account through social media plugs and share buttons. These call-to-action items were found to be especially prevalent for the Starbucks Rewards instant prize games, as depicted in Figure 6.

As a user navigates through the Starbucks Road Trip Morning Edition game, the user will notice they have many options that are given to them and the freedom to control the pace they would like to move from page to page. Oftentimes, the user is given the opportunity to opt-out of playing again or to share the game with their friends, through "Close" or "No, thanks" buttons. These examples, along with many other plug-ins, are call-to-action items which are functions associated with the need for autonomy. They allow users to navigate through the app freely without being made restricted to make certain decisions.

Finally, this app's game design takes narrative elements and meaningful stories into account. Within the Canadian version of the app; Canadian users can connect to the brand in celebrating Canada's $150^{\text {th }}$ Birthday, as promotional campaigns are all revolved around this celebration. While this is not a game element that relates directly to a player's performance, the theme acts as an analogy of real-world settings and provides meaning beyond a mere quest for the prize at 
hand. The narrative context here aligns with the personal interests of Canadians, and as such, has the ability to inspire and motivate players (Sailer, 2017).

\subsubsection{Desktop Website}

The Starbucks Rewards website occupies a section of the main public Starbucks website. Screengrabs of this data can be found in Appendix B. Since this loyalty program is designed to be used in-store, the program's main game functions are, for the most part, solely available on the application for the mobile device. It is evident Starbucks has taken this into account in the design of the desktop version, as less game elements have been employed on the desktop website. However, challenges that are offered on the app are also accessible from the program's desktop version, such as Bonus Star Bingo shown in Figure 7. On this section of the website, many previously discussed game design elements intend, once again, to evoke game-like experiences for the user. 


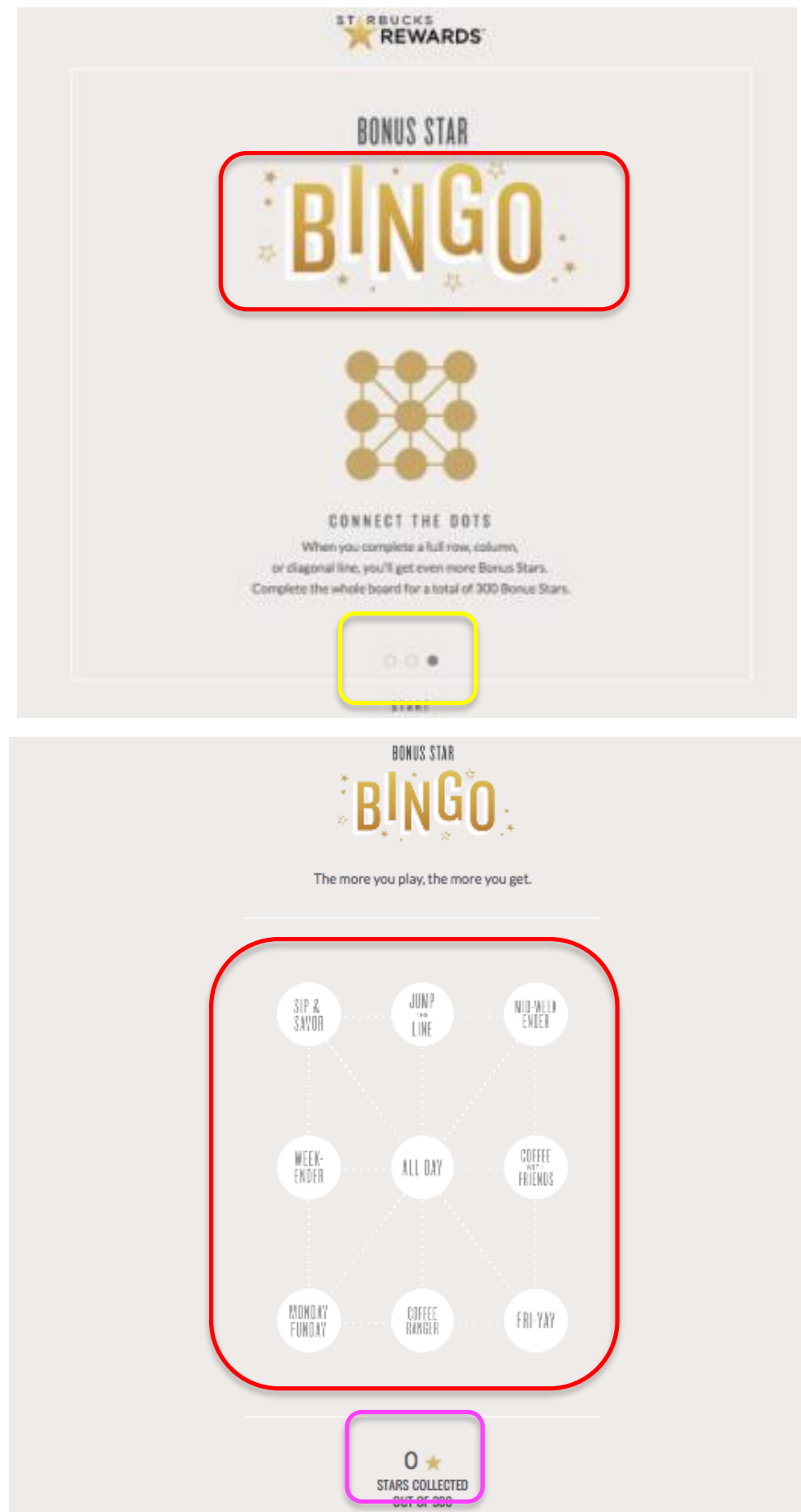

1 Incorporation of $\quad 2$ Familiar game: intuitive points application

3 Intuitive controls

Figure 5: Bonus Star Bingo, Desktop Website 
Bingo is a recognizable game that Starbucks consumers should be comfortable and familiar with playing, and thus the company must not need to be too detailed in the instruction of this game. This is ideal, as the player should not experience anxiety with the cognitive processing of information when approaching this challenge. Once a user has completed certain "tasks" as depicted by each space on the bingo card, each space will be "filled" until the user has built a straight line on the card, and is then awarded a prize. Figure 7 shows examples of this promotion, which includes game information pieces such as how-to instructions for the user, as well as a display of real-time points and levels that act as instant gratification pieces for the user. Figure 8 portrays an example where the loyalty program utilizes a user profile, which is beneficial in providing the player with a sense of personalization and autonomy. This profile section includes a dashboard, card balances, transaction history and account settings. 


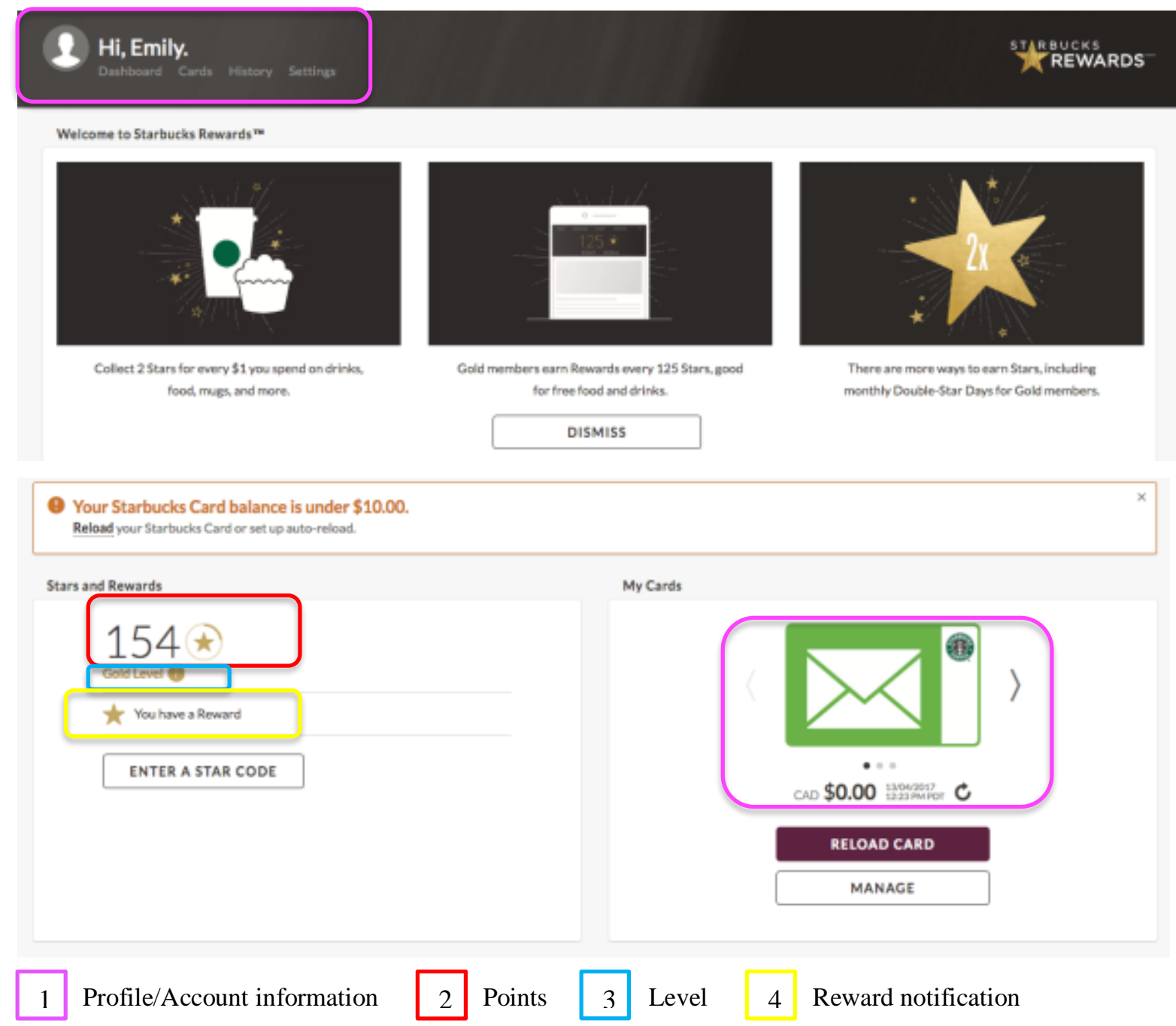

Figure 6: Profile and Account Information

\section{Game Mechanics Support Summary:}

Each of the game elements discussed in this section are properties of playability and can be addressed by the following need-motivations categories: autonomy, competence and relation. The categories are listed below, along with their associated game design elements which were uncovered throughout this analysis. 


\begin{tabular}{|c|c|}
\hline $\begin{array}{l}\text { Autonomy } \\
\begin{array}{l}\text { - Player has a sense of will; experiences } \\
\text { task meaningfulness } \\
\text { - Activities performed out of player's } \\
\text { personal interest } \\
\text { - Player experiences decision freedom; } \\
\text { does not feel completely controlled by } \\
\text { instructions }\end{array}\end{array}$ & $\begin{array}{l}\text { - } \quad \text { 'How to play' instructions } \\
\text { - } \quad \text { Personalization options } \\
\text { - } \text { Rewards for self } \\
\text { - } \text { Opt-out buttons } \\
\text { - User profile }\end{array}$ \\
\hline $\begin{array}{l}\text { Competence } \\
\begin{array}{l}\text { - Player can participate in challenges } \\
\text { - Player feels efficient } \\
\text { - Opportunities exist for player to acquire } \\
\text { - } \text { new knowledge or skills } \\
\text { Player feels optimally challenged }\end{array}\end{array}$ & $\begin{array}{l}\text { - Use of challenges } \\
\text { - 'How to play' instructions } \\
\text { - 'Stars' as points } \\
\text { - Levels } \\
\text { - Instant win challenges } \\
\text { - Instant rewards } \\
\text { - Road map } \\
\text { - Game board } \\
\text { - Bingo game familiarity } \\
\text { - Progressive information } \\
\text { - Intuitive controls }\end{array}$ \\
\hline $\begin{array}{l}\text { Relation } \\
\begin{array}{l}\text { - Player feels connected to others } \\
\text { - } \text { Player feels a sense of security } \\
\text { - } \text { social networks } \\
\text { - Player can be conveyed by a } \\
\text { - } \text { meaningful story } \\
\text { Player feels a sense of relevance }\end{array}\end{array}$ & $\begin{array}{l}\text { - Animations } \\
\text { - Social media plugs } \\
\text { - Share buttons } \\
\text { - Call-to-actions } \\
\text { - } \text { Canada } 150 \text { theme } \\
\text { - } \text { Privacy consages from Starbucks (Terms and Conditions) }\end{array}$ \\
\hline
\end{tabular}

\subsection{Rhetorical Analysis/Document Design Analysis}

The design of the overall interface and user experience of a web page or mobile application must be attractive to the user and plays a role in the gamification process. As put by Conaway and 
Garay, aesthetic design of a gamification platform enhances fun and allows for ease of platform use for the consumer (2014). In this section of the analysis, I will take screenshots from the mobile app and website to deconstruct non-game elements and discover how the media's visual and textual design work to persuade consumers in interacting with the Starbucks brand, and to optimize the overall experience for loyalty-building.

\subsubsection{Colour}

The use of colour on both platforms (web and mobile) is consistent to the usual Starbucks brand colours (black, green and beige tones), particularly for content that remains static (see Appendix C for screengrabs). Gold, however, is separate from the classic Starbucks brand colours, and represents Stars and the Gold Level. Metaphorically, gold is known to be associated with royalty, status and honour. This is the highest point level within the loyalty program, and when an individual reaches this amount of points the user is considered to be a Gold member. It is also worthwhile to note that the text colour, along with the colours of other foreground objects and graphics, always highly contrast its background. This allows the viewer to effortlessly pick out the most important messages, as well as have an overall more pleasant consumption experience.

\subsubsection{Aesthetic}

Well-chosen design aesthetic provides mood, tone and personality to a document, all of which are fundamental to a rhetorically effective artifact (Schriver, 1997). The design of this application takes a fairly minimalist approach in that white space is used in abundance and much of the text is spaced-out and thin, to give a light, yet sophisticated, feel. See Figure 7 for samples of this typography. 
White space, or negative

space, in two-dimensional

design refers to empty

space, or space that lies

behind the imagery or text.

Psychology research

\section{MORNINGS BEGIN HERE}

Start your morning at Starbucks". Each time you

do, you'll move along the map and earn Bonus.

Stars as you go.

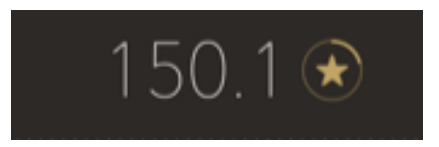

COMPLETE CHALLENGES

Collect 10 Bonus Stars for exch space you fill on the

game board. Remember, a sinele transaction

can count for multiple speces

stresses the importance of keeping a reader's cognitive load as light as possible (Schriver, 1997), and it is evident Starbucks stands for this idea in both the visual and textual design of its media. The use of white space, the sizing and the boldness of different texts allows for clear information hierarchy, enabling the viewer to organize and prioritize the most important information and be swiftly guided through the content. The use of blank space also increases legibility of the content, as per Schriver, and attracts and holds a reader's attention for longer (1997).

Appendix $\mathrm{C}$ portrays an example whereby information hierarchy is made clear in the composition of text and modification of visual weights in "Collect up to 175 bonus stars". Here, ' 175 ' is large and bolder to accentuate the most important point of information, the message that is at highest importance. "Bonus stars" is slightly larger and more prominent than "Collect up to", which is the second piece the reader should recognize. This interpretation of information hierarchy happens so fast that the reader does not even notice the complexity behind these design choices, but it is a purposeful marketing choice. Likewise, white space allows for clear information hierarchy. Certain elements, when surrounded by white space, are exaggerated and highlighted, breaking up the information and putting emphasis on the most meaningful messages 
for the reader.

Appendix $\mathrm{C}$ also portrays examples of rhetorical clusters, as depicted by ' 7 ' in the graphic. The designer has grouped information into rhetorical clusters to help the reader interpret the content accordingly. The aim here is to have certain textual elements work together as a functional unit within a document to put the reader at ease. Given the context of a mobile app, since content has less surface area to cover (versus a computer screen), the organization of information is more constrained and must therefore be prioritized through information hierarchy.

\subsubsection{Symbolism}

The app makes use of iconic elements, which bear a similarity or resemblance to what one might already know or conceive about a person or an object. As an example, it is noteworthy to mention the use of a star as a design element, incorporated in the Starbucks rewards logo and highlighted in Appendix C, '4'. The use of the star, both as a symbol and as a word, has influence as a rhetorical device. It is used repeatedly both in the actual logo and as cartoon drawings throughout the visual design of the app and website. These figures act as a repeated reminder of the brand for viewers, and allows Starbucks to be consistently associated with the symbolism of a star, regardless of whether it is directly incorporated in the logo with each instance. Second, a star has metaphorical associations with self-fulfillment, aspiration and being '\#1'. These associations contribute to the subconscious motivation for a player to 'exist', play, and progress within the loyalty program. 


\subsubsection{Typography}

Legible typography is necessary for effective document design, but just as important is the text's rhetorical appropriateness; designers wish to employ typography in a way that influences how the viewer organizes, remembers and perceives the content. The majority of the text used throughout the app is sans serif, which is considered highly legible, simple and has a modern appearance (Schriver, 1997). For this reason, sans serif fonts are usually preferred in a digital environment. Appendix C shows the use of sans serif used by itself(' 5 '). Sans serif is used by itself when a lot of text is grouped in one section, for example, 'How to play' instructions. However, there are also instances where serif and sans serif fonts are used together in the same document, as shown in Appendix $\mathrm{C}$, ' 6 '. Here, the app designers have employed this typographic

\section{Order}
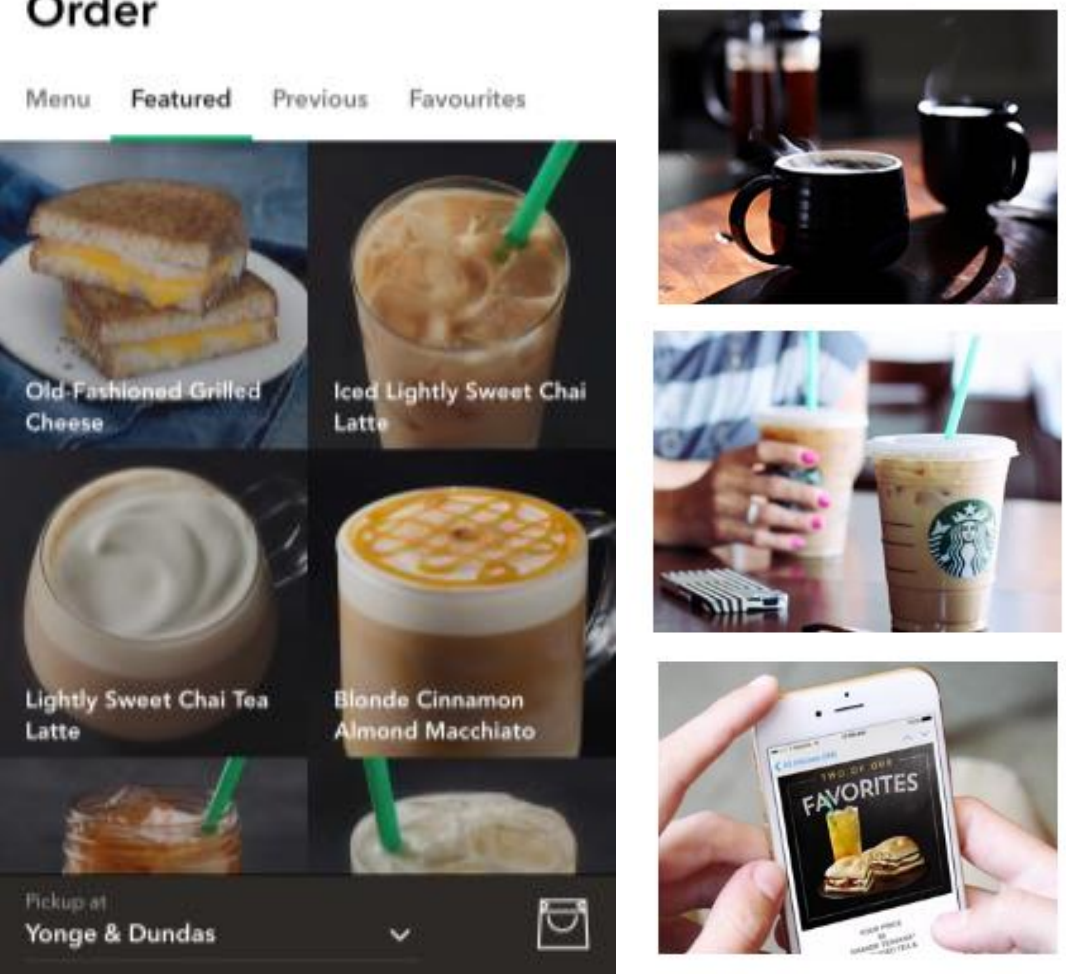

Figure 8: Examples of the use of professional photography

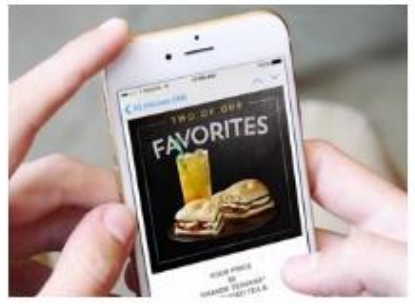

combination in instances

where the grouping of text

consists of a smaller number

of words. The combination

of these font types

complement each other, and

is advocated by designers as

it offers the "best of both

worlds" (Schriver, 1997, p.

257); serif faces offer a

visually rich texture, while

sans serif bear a spare,

uniform look. 


\subsubsection{Photography}

Photos of food appeal to the senses. Professional photography is used as a rhetorical element throughout the design of this loyalty program, with high-definition, digitally-enhanced photos of everything from lattes, to sandwiches, to cookies. Humans react to aesthetic qualities of food images not only on sensory and cognitive levels, but also emotional levels (Fisher et al. 2012)., so attractive food photography will not only entice consumers to purchase product, but will also effect a consumer's overall brand attitudes. In addition, the use of well-crafted, high-definition photography establishes a level of professionalism and credibility for the company's food offerings. Starbucks is strategic in its styling of food; everything from the lighting, the angle and the texture of each food item has been taken into consideration so as to present a mouth-watering image to the viewer. This technique works hand-in-hand with the pre-order feature on the app, as an individual can go from flipping through food images to actually consuming that same food item, all in a matter of minutes.

Photography that includes human hands in the frame adds a creative personal element to the app experience and help brings the brand's personality to life; figure 10 shows photos of customer hands at a table holding an iced coffee, and hands holding an iPhone while navigating through the Starbucks app. 


\subsection{Discussion}

Current research today understands gamification to be the use of elements of game design in a typically non-game context. Since certain game design elements will elicit certain psychological effects, these elements are tools that guide consumers' motivations to play a game. The basic building blocks of gamification applications are the game design elements themselves (Sailer, 2017). Starbucks applies gamification in an advertising context and uses it as a tool to cater to the psychological and social motivations of human beings; more specifically, the social needs for autonomy, competence and relation, which predict enjoyment as well as future game-playing habits (Sailer, 2017).

In addition, through the guidance of a visual analysis, it is evident that website and app designers for Starbucks have been considerate of the context in which consumers engage with content. Taking gamification support elements and document design factors into consideration, it is clear that the Starbucks Rewards loyalty program carries out the rhetorical function of persuasion using three appeals: ethos, pathos and logos.

\section{Ethos}

The game and visual design of Starbucks Rewards achieves the ethical appeal for the user through the establishment of trust and credibility. First, Starbucks puts emphasis on recognisability; branding is prevalent throughout the app and website, and is consistent with what consumers are familiar with during an in-store experience. In addition, using gold as a colour to represent the brand and the game's points is an appeal to ethos as the brand is associated with a certain level of royalty and status, contributing to the brand's overall 
credibility. The typography within the document design of the media incorporates sans serif font, as outlined in the analysis section, which is considered to be a highly legible font for digital platforms as it incorporates a simple and modern appearance.

Starbucks also establishes trust with the user by ensuring the user that their privacy and security is respected through a Terms and Conditions page. Lastly, the use of professional food photography speaks to the ethos used in Starbucks Rewards. The lighting and definition of these photos contribute to both a consumer's cognitive and emotional sensory levels. Since the styling of food in the photography is quite exhaustive, it suggests the food was crafted by a skilled individual; this is the level of quality an individual would expect to receive from this restaurant, once again reinforcing credibility in the brand. The company establishes a sense of compatibility by applying campaigns that foster a sense of community to the mobile app, such as the \#150Wishes campaign, as well as the campaign that celebrates Canada 150. Other app attributes such as the Mobile Order \& Pay function, and additionally a map function with store listings directly on the app, aid in establishing a certain level of credibility for this medium to act as a true marketplace.

\section{Pathos}

The pathos appeal for websites is dependent on playfulness, empathy and tangibility. The interactive nature of the Starbucks app aims to contribute to brand loyalty by providing users with an entertaining experience. In addition, many aspects of visual design as highlighted in the

analysis are feeling-generating elements, and are a part of the create the brand's overall aesthetic; ultimately creating positive connotations with the brand. These elements include use of 
typography, colour, decoratives, animations, effective use of white space, and clear information hierarchy.

Animations utilized throughout the app and website increase human cognitive and emotional processing, and, as explained by Jin, can augment a viewer's attention in low-involvement products (such as coffee, in the given situation) (2011). The use of animation causes a viewer's attention to be held longer, accentuating the time to consume information. In addition, animations speak to the pathos dimension in that they produce high arousal levels for the consumer, leading to greater brand recall.

Starbucks plays to a consumer's senses by adding narrative elements to the program, and themed meaningful promotions that its audience can associate with. The Canada's 150 Birthday promotional campaign portrays an example of this; app users can emotionally connect with this type of campaign as their own cultural interests are being taken into consideration. Once again, just as building a sense of community establishes compatibility in the ethos of the loyalty program, consumers are appealed by social motives, so experiencing a sense of community also brings about an emotional element. The integration between the loyalty program and a user's social network has the same effect here, as well as the integration of personalized messages from the company, social media plug-ins, etc.

Properties of playability boost the overall enjoyment factor of the loyalty program; this includes gamification elements that satisfies a player's motivational need for competence. As highlighted in the analysis section, these elements include positive feedback (the accumulation of points, 
levels) and reward (free merchandise). Furthermore, a committed customer is going to feel pride when reaching the 'Gold' level of the program; the wording "Gold" itself is a trope for royalty and power. It is also noteworthy to mention the repeated use of stars as rhetorical tropes in the app and on the website as a rhetorical device. Stars, as symbols, are associated with the Starbucks brand, and repeated brand exposure results in increased attitude perceptions of the brand. A brand will become more favourable to a consumer the more times they notice it (Keller \& Campbell, 2003).

\section{Logos}

Logos, as a rhetorical appeal, is tied to a customer's logic. Information supports the consumer's decision-making process; therefore, key factors to effective design include the amount of information, the display of information, and the effort of navigation for the user. Information transfer to the user is achieved through indicatives, which are action-provoking forms of text that prompt an audience to take a certain action, and informatives, which act to further the understanding of an audience (Amare and Manning, 2007). Starbucks employs a sufficient amount of information regarding the company and products on Starbucks Rewards sites. Examples of information include, but are not limited to: game instructions, food and drink information, store directory information, rewards program guidance, company messages, and other gamification-specific elements.

Just as points and levels serve the rhetorical appeal of pathos, they also act as informational performance feedback. Users aim to reach certain positions or rankings, and levels set clear performance targets for players to aspire to. They are thus an important logical appeal. 
As put by Phillips and McQuarrie (2004), if a form of art adheres to a familiar template, it is considered a rhetorical figure. Starbucks' use of Bingo, for example, and other familiar game templates is rhetorical in nature from the user's viewpoint; the player experiences little anxiety while figuring out a game's instructions, with more time to spend money and make purchases through the app, and to reach the desired end goal: achieve a straight line, or "Bingo", and beat the game.

Likewise, the use of intuitive game controls throughout the design of both the Starbucks Rewards website and app allow for stress-free navigation, less effort for the player, and therefore a more pleasurable experience with the rewards program. Additionally, visual design features such as optimal typography, rhetorical clusters, colour contrast and use of white space serve to reduce the user's cognitive load and allow for focus on the most important messages. As an example, certain typography is used strategically to slow down the reader on purpose (Schriver, p. 274). Accentuating the time it takes to consume information allows for a greater familiarity of that information, regardless of whether the processing of the information is semantic (words, logos, names) or sensory (images, attributes, animations).

After a thorough analysis, it is evident that the web designers for Starbucks Rewards have been cognizant in maximizing usability and the user experience through the provision of a configurable interface and intuitive controls to navigate the platform, thereby appealing to logos. 
Since Starbucks Rewards has implemented an aspect of gamification to their platform, the component of competition within the game becomes a challenger motivator to the consumer of the program. This causes the consumer to elicit both behavioural and emotional responses around that brand. With loyalty rewards providing instant gratification for the user, powerful incentives are established for returning players. Starbucks has carefully employed principles of design to manipulate the communicative intent of visualizations.

What is thought-provoking about Starbucks and its iconic rewards program is that the company itself sells and stands for a product which consumers do, in fact, have a physical dependence for: coffee. Not only does Starbucks cultivate a devoted, addictive consumer following through a manipulative loyalty program, but the product at hand also has addictive properties. Through this analysis, it is clear that the company has considered the collaboration between the marketplace and marketing, contributing to the power that mobile technology possesses by leveraging the dynamics of capitalism. 


\subsection{Conclusions}

This study analyzed the Starbucks Rewards loyalty marketing efforts across the company's desktop website and mobile application. With connectivity to today's media being ubiquitous, companies must cater their digital marketing to the "always-on" consumer. In addition, content marketing must be crafted with the intention of tapping into a consumer's subconscious, where a large majority of human cognition occurs, to build a liking to a brand. This process aims to work customers up a relationship ladder whereby familiarity of a brand transforms into brand satisfaction, leads to trust of the brand and then eventually an attitudinal loyalty associated to that brand.

Through a gamification analysis and a visual analysis of the document design used in the Starbucks Rewards program, I was able to conclude that this loyalty program has employed game-like elements as motivational mechanisms to satisfy a consumer's need for autonomy, competence and relation. In addition, the three modes of persuasion were evident in an analysis of the app and website's user interface design. Examples of ethos, pathos and logos were employed in the media's use of colour, aesthetic, typography and strategic composition of informational elements.

In conclusion, it is evident the company has been purposeful in the development of their digital loyalty marketing efforts so as to develop customer loyalty through psychological mechanisms and alter consumer behavior in favor of corporate objectives. Starbucks has carefully employed principles of design to manipulate the communicative intent of visualizations within their digital 
media. This has allowed the Starbucks Rewards app to capitalize on the human mind for consuming visual information, thereby shaping memory, comprehension and perception.

The following section outlines considerations for future research. 


\subsection{Limitations and Considerations for Future Research}

For future research considerations, it would be valuable to deconstruct the textual aspects of the Starbucks' app and website in terms of tone and grammar, rather than exclusively looking at text in a visual or iconic sense. While typography can be telling, the analysis of language use can reveal metaphorical and rhetorical devices in words, and would be able to further contribute to how the three modes of persuasion have been employed in a loyalty program to build consumer preferences. Also, it would be beneficial to dive further into the underlying technologies used in game applications to understand the thought process behind deciding on certain technological aspects of the app. Unfortunately, this area of research did not fit within the scope of this Major Research Paper. 


\section{Bibliogaphy}

Amare, N., \& Manning, A. (2007). The language of visuals: Text + graphics = visual rhetoric. IEEE Transactions on Professional Communication, 50(1), 57.

Andrejevic, M. (2007). iSpy: Surveillance and power in the interactive era University Press of Kansas.

Aparicio, A. F., Vela, F. L. G., Sánchez, J. L. G., \& Montes, J. L. I. (2012, October). Analysis and application of gamification. In Proceedings of the 13th International Conference on Interacción Persona-Ordenador (p. 17). ACM.

Boerman, S. C., Reijmersdal, v., E.A, \& Neijens, P. C. (2012). Sponsorship disclosure: Effects of duration on persuasion knowledge and brand responses. Journal of Communication, 62(6), 1047-1064. doi:10.1111/j.1460-2466.2012.01677.x

Bowers, J. (2008). Introduction to two-dimensional design: Understanding form and function (2nd ed.) Wiley.

Bryman, A., \& Bell, E. (2016). Social research methods. Fourth Canadian Edition. Don Mills: Oxford University Press.

Conaway, R., \& Garay, M. C. (2014). Gamification and service marketing. Springerplus, 3(1), 111. doi:10.1186/2193-1801-3-653 
Dale, S. (2014). Gamification: Making work fun, or making fun of work? Business Information Review, 31(2), 82-90. doi:10.1177/0266382114538350

Fisher, H., du Rand, G., \& Erasmus, A. (2012). The power of food images to communicate important information to consumers. International Journal of Consumer Studies, 36(4), 440-450. doi:10.1111/j.1470-6431.2011.01068.x

Gibbs, G. (2007). Thematic coding and categorizing. (pp. 38). London: SAGE Publications, Ltd. doi:10.4135/9781849208574.n4

Golumbia, D. (2009). Games without play. New Literary History, 40(1), 179-204.

Harwood, T., \& Garry, T. (2015). An investigation into gamification as a customer engagement experience environment. Journal of Services Marketing, 29(6/7), 533-546. doi:10.1108/JSM-01-2015-0045

Henderson, C. M., Beck, J. T., \& Palmatier, R. W. (2011). Review of the theoretical underpinnings of loyalty programs. Journal of Consumer Psychology, 21(3), 256-276. doi:10.1016/j.jcps.2011.02.007

Hofacker, C. F., De Ruyter, K., Lurie, N. H., Manchanda, P., \& Donaldson, J. (2016). Gamification and Mobile Marketing Effectiveness. Journal of Interactive Marketing, 34, 
25-36.

Jin, C. (2011). The role of animation in the consumer attitude formation: Exploring its implications in the tripartite attitudinal model. Journal of Targeting, Measurement and Analysis for Marketing, 19(2), 99-111. doi:10.1057/jt.2011.8

Kirkpatrick, G., Mazierska, E., \& Kristensen, L. (2016). Marxism and the computer game. Journal of Gaming \& Virtual Worlds, 8(2), 117-130.

Kucuk, S. U. (2015). A semiotic analysis of consumer-generated antibranding. Marketing Theory, 15(2), 243-264. doi:10.1177/1470593114540677

Latif, W. B., Islam, M. A., \& Idris Bin Mohd Noor. (2014). A conceptual framework to build brand loyalty in the modern marketing environment. Journal of Asian Scientific Research, 4(10), 547.

Leach, J. (2000). Rhetorical analysis. Qualitative researching with text, image and sound, 207226.

Mahoney, M. (2003, January 13). The Subconscious Mind of the Consumer (And How To Reach It). Retrieved May 28, 2017, from http://hbswk.hbs.edu/item/the-subconscious-mind-ofthe-consumer-and-how-to-reach-it

McGuigan, L., \& Murdock, G. (2015). The medium is the marketplace: Digital systems and the 
intensification of consumption. Canadian Journal of Communication, 40(4), 717.

Mekler, E. D., Bruhlmann, F., Tuch, A. N., \& Opwis, K. (2017). Towards understanding the effects of individual gamification elements on intrinsic motivation and performance. Computers in Human Behavior, 71, 525. doi:10.1016/j.chb.2015.08.048

Michalik, U., \& Michalska-Suchanek, M. (2016). The persuasive function of rhetoric in advertising slogans. Journal of Accounting and Management, 6(1), 45-58.

Mittal, B. (1988). The role of affective choice mode in the consumer purchase of expressive products. Journal of Economic Psychology, 9(4), 499-524. doi:10.1016/01674870(88)90016-5

My Starbucks Rewards. (n.d.). Retrieved January 26, 2017, from https://badgeville.com/wiki/mystarbucksrewards

Oswald, L. (2015). Creating value: The theory and practice of marketing semiotics research (First ed.) Oxford University Press.

Pauwels, L. (2012). A multimodal framework for analyzing websites as cultural expressions. Journal of Computer-Mediated Communication, 17(3), 247-265. doi:10.1111/j.10836101.2012.01572.x 
Phillips, B. J., \& McQuarrie, E. F. (2004). Beyond visual metaphor: A new typology of visual rhetoric in advertising. Marketing Theory, 4(1-2), 113-136.

doi:10.1177/1470593104044089

Roderick, L. (2017, ). Why starbucks thinks 'being everywhere' works against the brand. Marketing Week (Online)

Ryan, R. M., Rigby, C. S., \& Przybylski, A. (2006). The motivational pull of video games: A self-determination theory approach. Motivation and emotion, 30(4), 344-360.

Sailer, M., Hense, J. U., Mayr, S. K., \& Mandl, H. (2017). How gamification motivates: An experimental study of the effects of specific game design elements on psychological need satisfaction. Computers in Human Behavior, 69, 371-380. doi:10.1016/j.chb.2016.12.033

Schell, J. (2008). The art of game design: A book of lenses Elsevier/Morgan Kaufman

Schriver, K. A. (1997). Dynamics in document design: Creating text for readers Wiley Computer Pub.

Starbucks Road Trip: Morning Edition. (2016). Retrieved March 26, 2017 from https://www.starbucksroadtrip.ca/public/fulfillment/rules.pdf

Thomas, D. R. (2006). A general inductive approach for analyzing qualitative evaluation data. American Journal of Evaluation, 27(2), 237-246. doi:10.1177/1098214005283748 
Tirdatov, I. (2014). Web-based crowd funding: Rhetoric of success. Technical Communication, 61(1), 3 .

Titscher, S., Meyer, M., Vetter, \& Wodak, R. (2000). Methods of Text and Discourse Analysis. London: Sage.

Welhausen, C. A. (2016). Toward a topos of visual rhetoric: Teaching aesthetics through color and typography. Journal of Technical Writing and Communication, , 4728161664675. doi:10.1177/0047281616646752

Winn, W., \& Beck, K. (2002). The persuasive power of design elements on an e-commerce web site. Technical Communication, 49(1), 17-35.

Zack, R. (2017). McDonald's move to mobile ordering will be closely watched. Mobile Payments Today. News Features 


\section{APPENDIX A: MOBILE SCREENGRABS}


Appendix A: Mobile Screengrabs

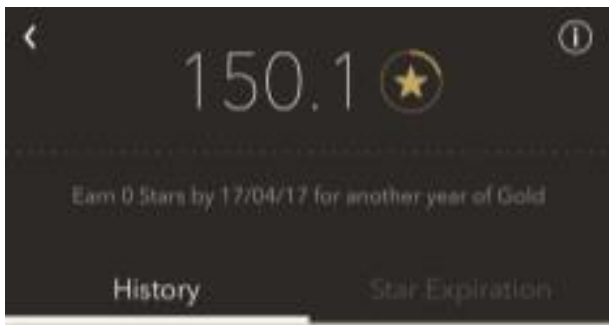

\section{March}

4.9 Stars Eamed

is My Card (7940)

Bay \& Dundas (TEC)

4.7 Stars Earned

My Card (7940)

$\$ 2.36$

Birthday Reward

Expired

Mar 14

Birthday Reward

Available Until Mar 14

125.0 Stars Redeemed

Mar 08

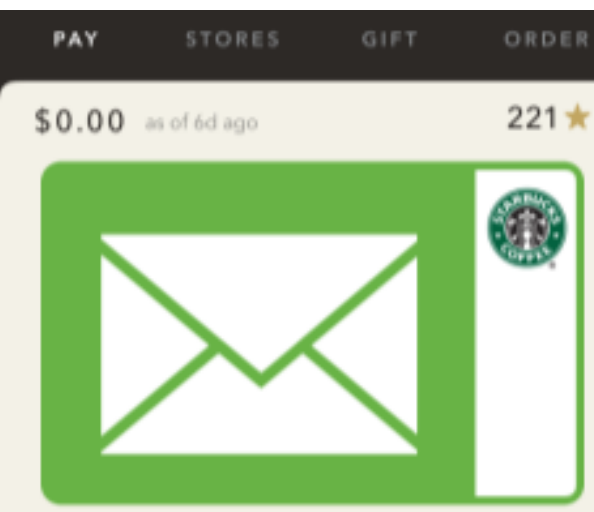

$\bullet \bullet$

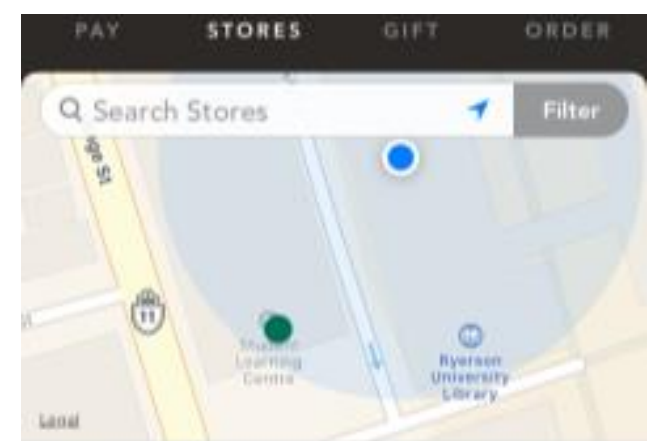

Compass a Ryerson

347 Yange of

$54 \mathrm{~m}$

Open until 10:00 PM

Yonge \& Gerrard

407 Yonge Street

Open until 10:00 PM.

$181 \mathrm{~m}$

Yonge \& Dundas

10 Dundas St E

$199 \mathrm{~m}$

Open untl 11:00 PM

PAY

\section{RELOAD}

\section{Order}

Menu Featured Previous Favourites

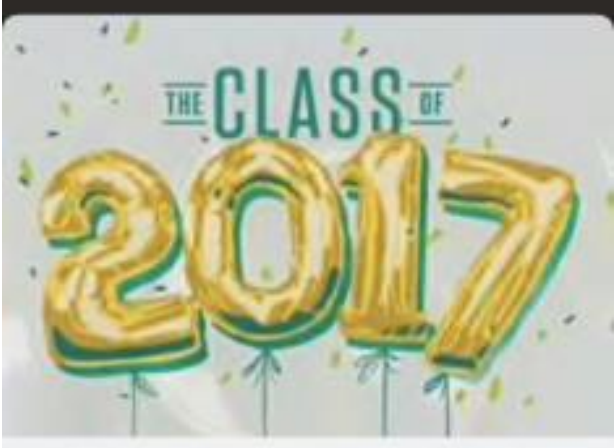

FATHERS DAY
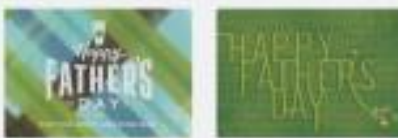

TEACHER

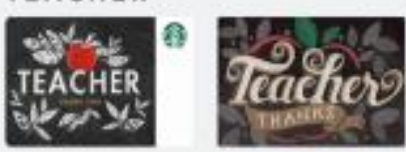

GRADUATION

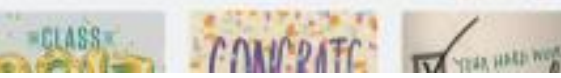

See All >

See All >

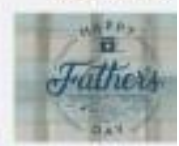

See All >
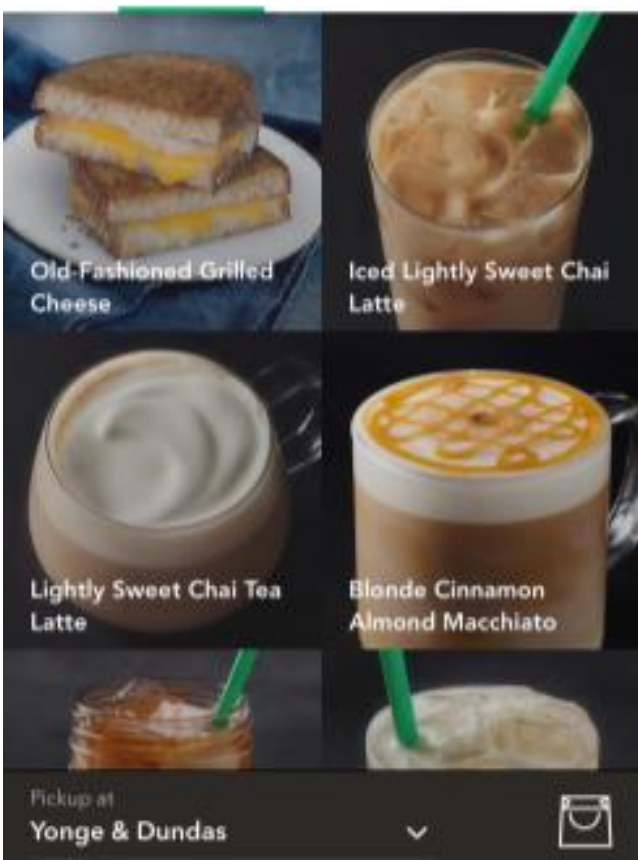

Church \& Gerrard

66 Gerrard Street East

Open until 10.00 PM

$0.2 \mathrm{~km}$

\section{Order}

Menu Featured Previous Favourites

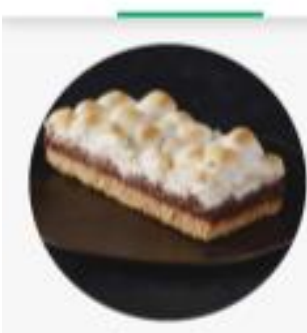

Smores Bar

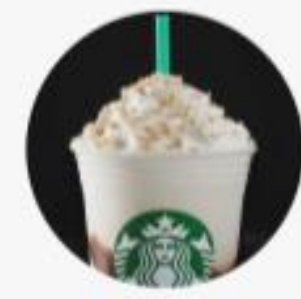

S'mores Creme

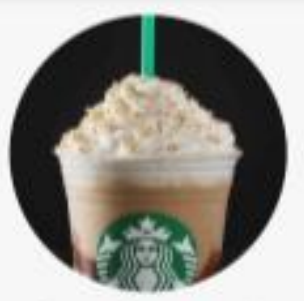

S'mores Frappuccino*

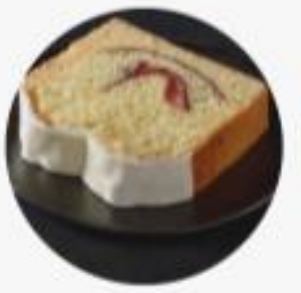

Lemon Raspberry Loaf
Mekup at

Bay \& Dundas (TEC) 


\section{Order}

Menu Featured Previous Favourites

\begin{tabular}{ll}
\hline DRINKS & $>$ \\
Featured Drinks & $>$ \\
Espresso Drinks & $>$ \\
Iced Coffee & $>$ \\
Clover Brewed@ Coffee & $>$ \\
Brewed Coffee & $>$ \\
TEAVANA@ Teas & $>$ \\
Frappuccino@ & $>$ \\
Starbucks Refreshers ${ }^{\mathrm{N} M}$ & $>$
\end{tabular}

$\times$

\section{Order}

Menu Featured Previous Favourites

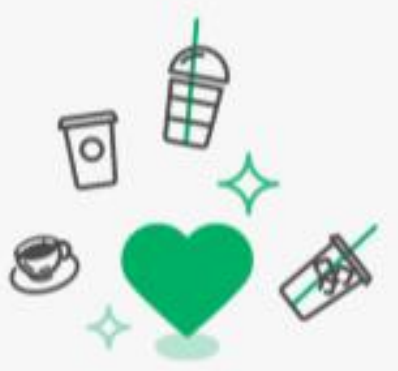

It's OK to like some things more than others.

When you favourite an item it will appeat here to quickly order again.
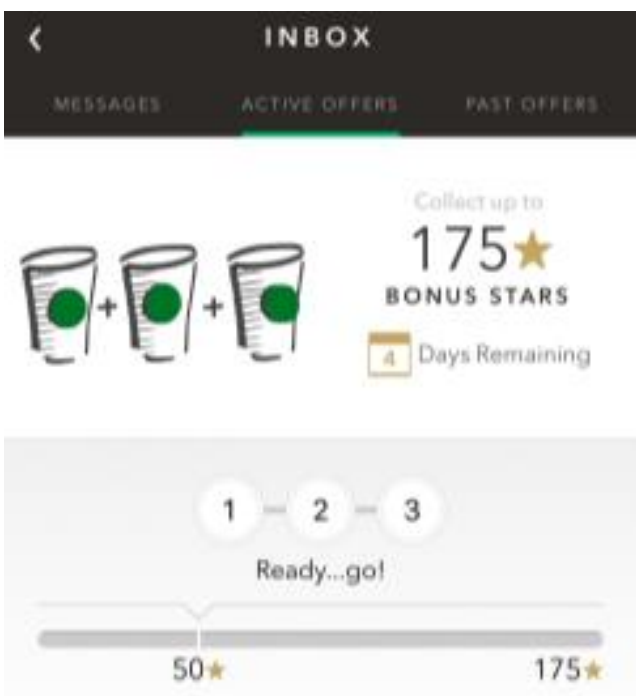

Star Dash

How to Play

Tap 'Start' to activate this challenge, and make purchases through 4/3/2017

- Make 3 purchasess? collect 50 Bonus Stars

- Make 5 purchaseds collect 175 Bonus Stars

Show More

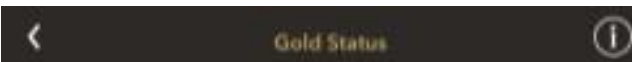

\section{Order}

Menu Featured Previous Favourites

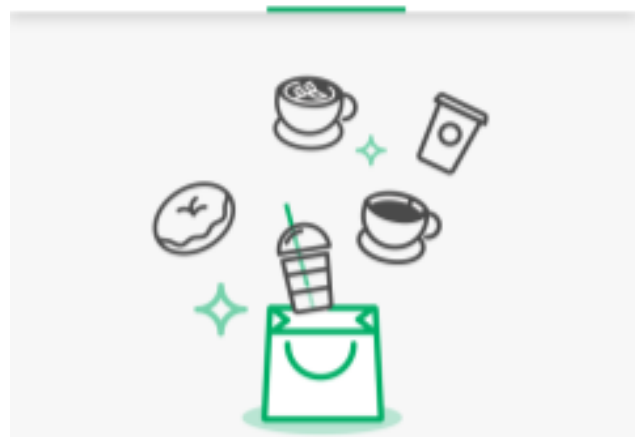

When history repeats itself.

Previous orders will appear here to quickly order again.

Pickup at

Yonge \& Dundas

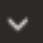

\section{STARBUCKS REWARDSTM}

\section{Done}

Green Level 0-299 Stars

Free Birthday food or drink

Free same-day in-store refills on brewed coffee \& tea

Jump the line: Order and pay ahead from the Starbucks@ app

Pay with your phone at the register

Member-only events and exclusives

Special offers over email and in the app

For full details see starbusks:calrewards

At participating stores. Some reutrictions apply.

Collect 2 Stars for every $\$ 1$ spent Get a free drink or food Reward every 125 Stars

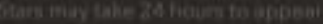

125 * Apply 125 stan for a Reward

\section{Gold Level 300+ Stars}

All the Green Level benefits, plus:

Rewards - Free drink or food every time you collect 125 Stars 
Monthly Double-Star Days

A personalized Gold Card

For full details see starbucks.celrewatds.

At participating stores. Some restrictions apply.

\section{Starbucks Rewards ${ }^{\mathrm{TM}}$ Program Details}

\section{How does it work?}

Starbucks Rewards members earn 2 Stars foe every $\$ 1$ spent at participating Starbucks stores. Stars are used to track the Rewards and benefits members eam in the Starbucks Rewards program.

\section{What are the benefits and Rewards?}

Now members start with Green Level. Collect 300 Stars over a 12-month period to get Gold Status. After 300 Stars, every 125 Stars you collect can be redeemed for a Reward, good for a free drink or food item.

\section{Do my Stars or Level expire?}

The Stars you eam as a Green member will expire after 12 months, if you do not reach Gold Status. and your 5 tar balance will be reset to zero (O).

As a Gold member, the Stars you earn towards Rewards will expire after 6 months: Your oldest 5 tars will always be applied towards your Reward first. To maintain Gold Status you must eam 300 Stars within 12 months.

For example, if you earn 10 Stars on June 16 and 15 Stars on June 24, your total Star balance for the month-25 Stars-will expire on January 1 We'll send you a reminder via email before your Stars or Gold Status expire

\section{Can I collect Stars on less uneven amounts?}

Yes, your change counts towards partial Stars. We'll keep track of all your partial Stars and apply them to your total Stars:

For example, if you spend \$6.20 (not including tax, tips, alcohol or other exceptions), you will earn 12.4 Stars.
How much of what I spend is applied toward Stars?

You earn 2 5tars per $\$ 1$ spent on coffee, food, drinks, and merchandise when you pay with your registered Starbucks Card or app. However in most stores, you do not earn Stars on taxes, tips, fees, alcohol, or donations. So, for example, if you spend $\$ 5$ on your beverages plus $\$ 0.50$ in tax, your total amount applied towards Stars is $\$ 5$ and you earn 10 Stars

Please note that you don't earn Stars on any cand. to-cand transactions

Some restrictions apply. Rewards may be redeemed at participating stores only and exclude alcohalic beverages and multi-serve food and beverage items. Birthday reward expires one day after your birthday. Stars lincluding partial Stans) earned toward free food and drink rewards expire 6 months after they are earned. Stars may not be eamed on purchases of alcohol and Starbucks Cards. Taxes, tips, donations, and fees Isuch as delivery fees, shipping and handling fees, gitt wrapping fees and bag fees) may also be excluded. Free refilis for in-store, same day

most stores, you do not earn stars on taxes, tips. fees, alcohol, or donations. So, for example, if you spend $\$ 5$ an your beverages plus $\$ 0.50$ in tax, your total amount applied towards Stars is $\$ 5$ and you eam 10 Stars

Please note that you don't earn Stars on any cardto-card transactions

Some restrictions apply. Rewards may be redeemed at participating stores only and exclude alcoholic bevereges and multi-serve tood and beverage items. Birthday rewand expires one day after your birthday, Stan (inciuding partial Stars) eamed toward free food and drink rewards expire 6 months after they are eamed. Stars may not be earned on purchases of alcohol and Starbucks Cards. Taxes, tips, donations, and fees (such as delivery fees, shipping and handling fees. gift wrapping fees and bag fees) may also be excluded. Free refills for in-store, same day visit. Must opt-in to receive promotional email from Starbucks to receive special email offers. Personalized Gold Card is gold-colored only, it is not gold metal. Mobile Order and Pay may not be available at all locaticns. See starbucks caftermi for details 


\section{Campaign 1: Starbucks Road Trip: Morning Edition}
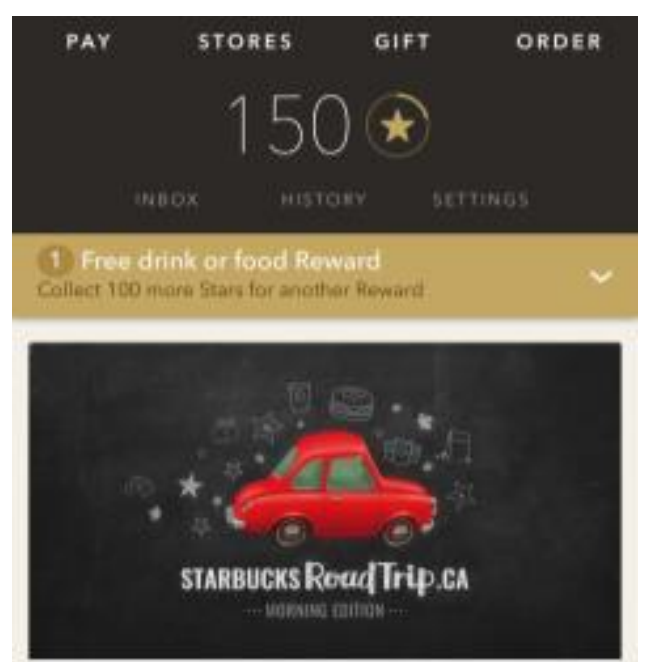

Who's ready for a road trip?

Play Starbucks Road Trip, Morning Edition for a chance to win thousands of prizes. Now until April 30.

PLAY NOW

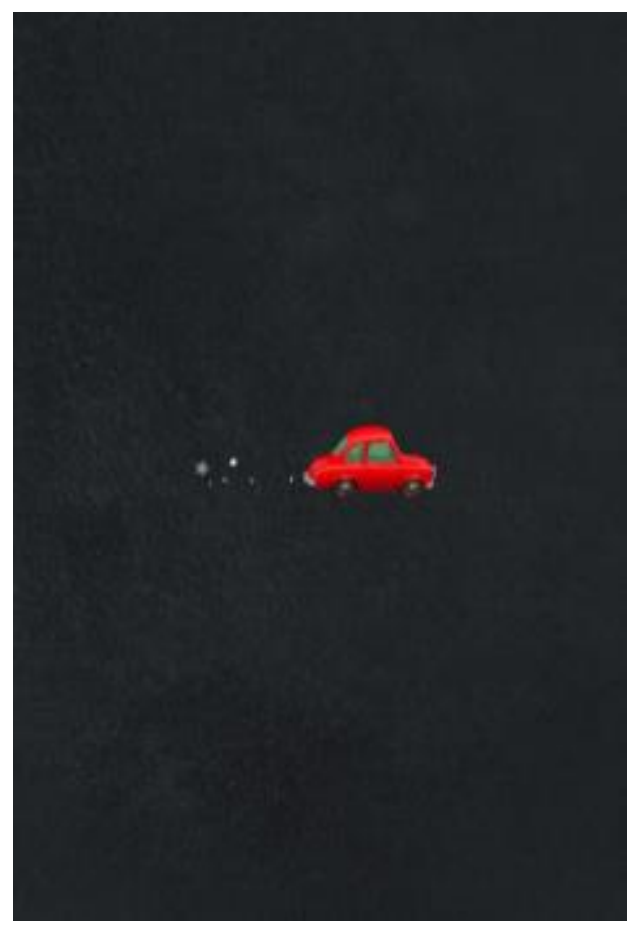

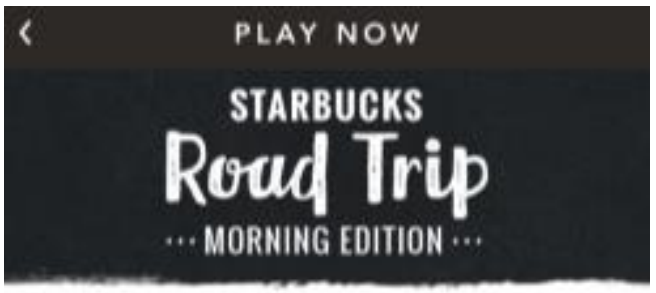

Let's celebrate Canada 1501

Thousands of prizes avallable.

Sign into Starbucks Rewards ${ }^{\text {thise }}$ to begin your

countrywide road trip.

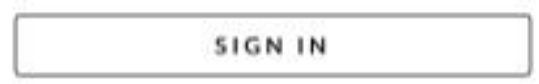

NOT A MEMUERT JOIN NOW
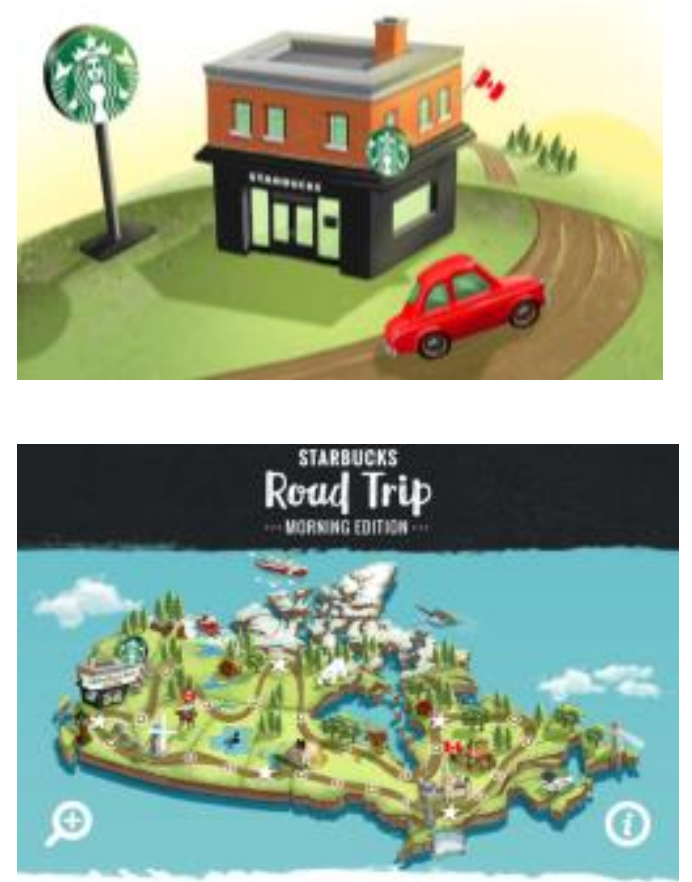

\section{MORNINGS BEGIN HERE}

Start your morning at Starbucks". Each time you do, you'll move along the map and earn Bonus Stars as you go.

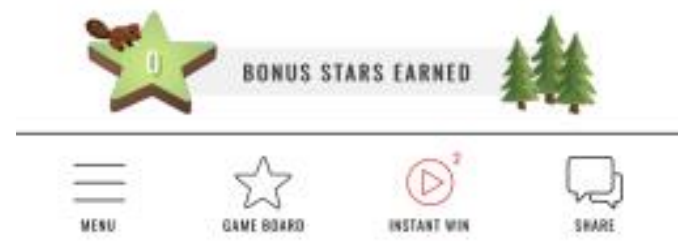

TURN YOUR GIFT CARD INTO A REWARDS CARD

6

My Account $\bullet \equiv$

\section{Request for permission}

Authorize 5 tarbucks Road Trip to access your

Starbucks account?

This application will be able to:

- Access my profile information.

- Access my 5tarbucks Card transactions

- Access information about my payment methods.

- Access information about Starbucks Rewards.

By authorizing an application you continue to operate under Starbucks Terms of Use and Privacy Policy.

If you change your mind, you can always revoke authorization by selecting fisconnect from the same location you initiated this connection.

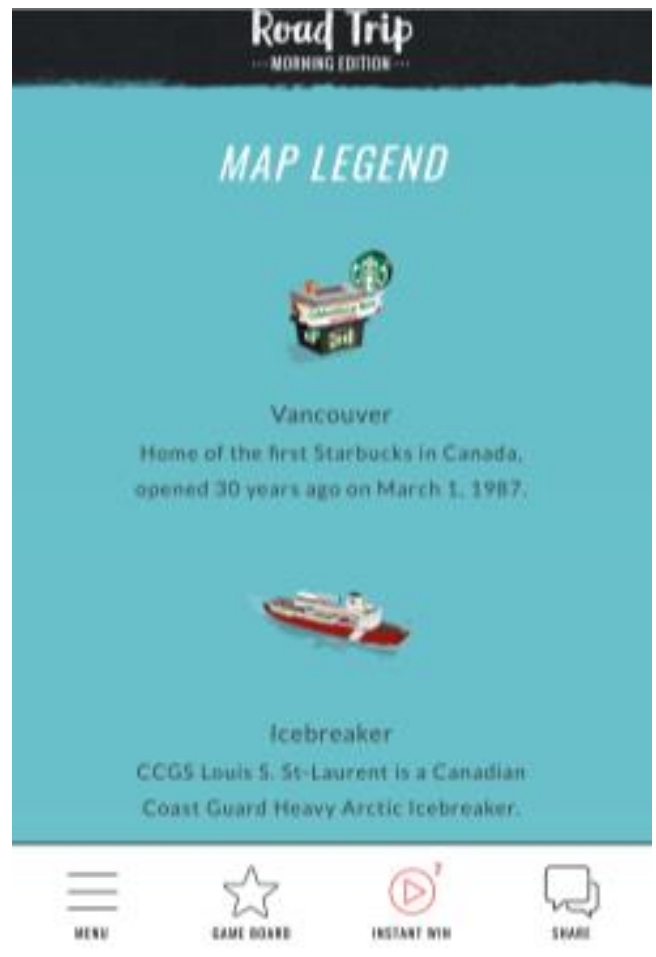




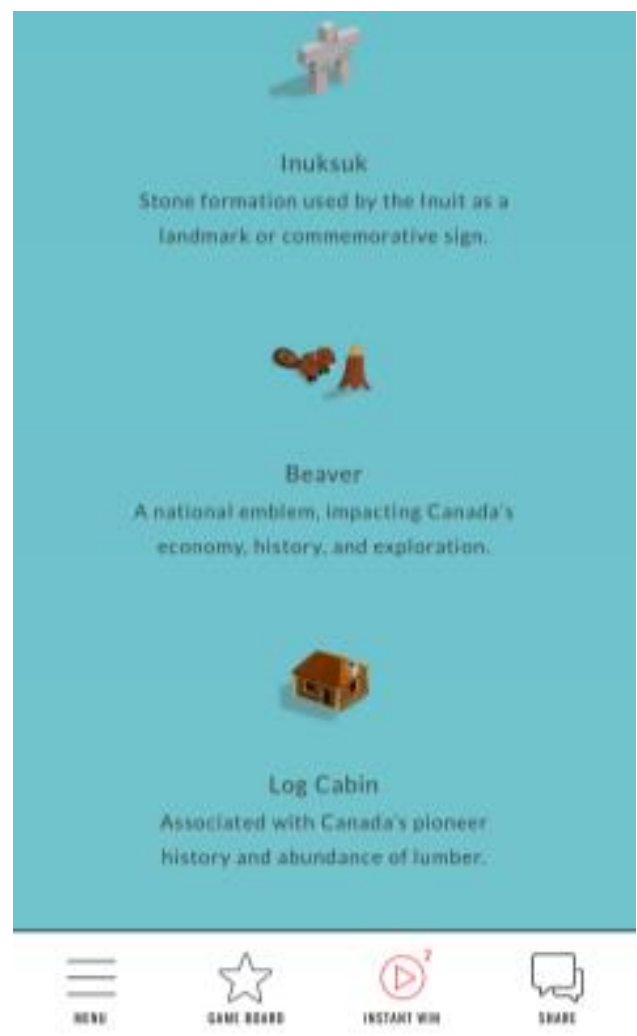

\section{HOW TO PLAY}

Simply make a morning purchase to start earning Bonus Stars and advance along the map, with chances to win prizes along the way:
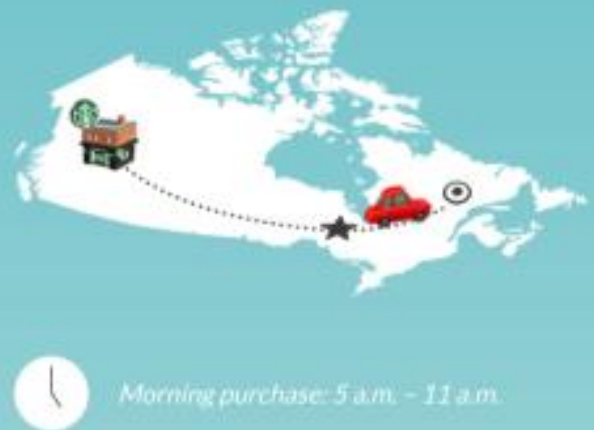

Morming purchase-5am -11 am

SKIP

\section{MORNINGS BRING BONUS STARS}

\section{Earnone Bonus Star for each}

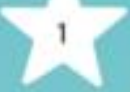
morning purchase you make:

riletwem Sam-11 ams

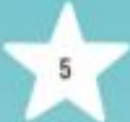

Earn an additional 5 Bonus Stars for every fifth morning purchase you make.

Earn an additional 150 Bonus

150 Stars when you complete one trip around the map, Cheers!

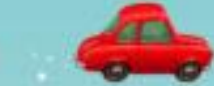

SKIP

\section{NEXT UP. INSTANT WIN GAME}

For every purchase you make, any time of day, you'll earn an instant win play:

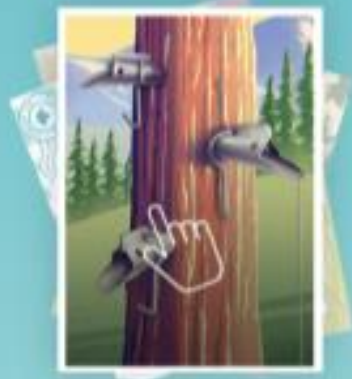

As winter melts into spring, explore five unique instant win games.

$=0$

PLAY

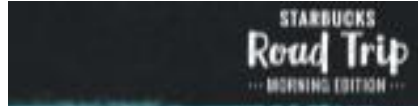

\section{LET'S GO}

A new adventure begins here

Pick a game and you could win ene of thousands of prizes, includine free coffee for a year. (That's one tall turewed coffee each day for 365 days.
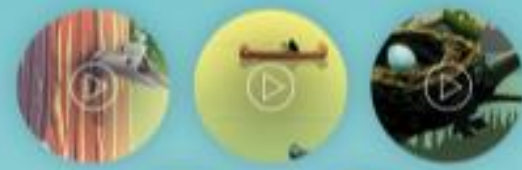

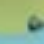
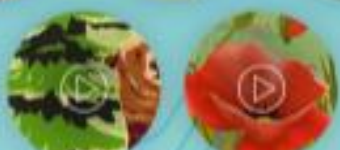

Maple syrup, anyone? Tap on any spout to sec if you're a lucky winner
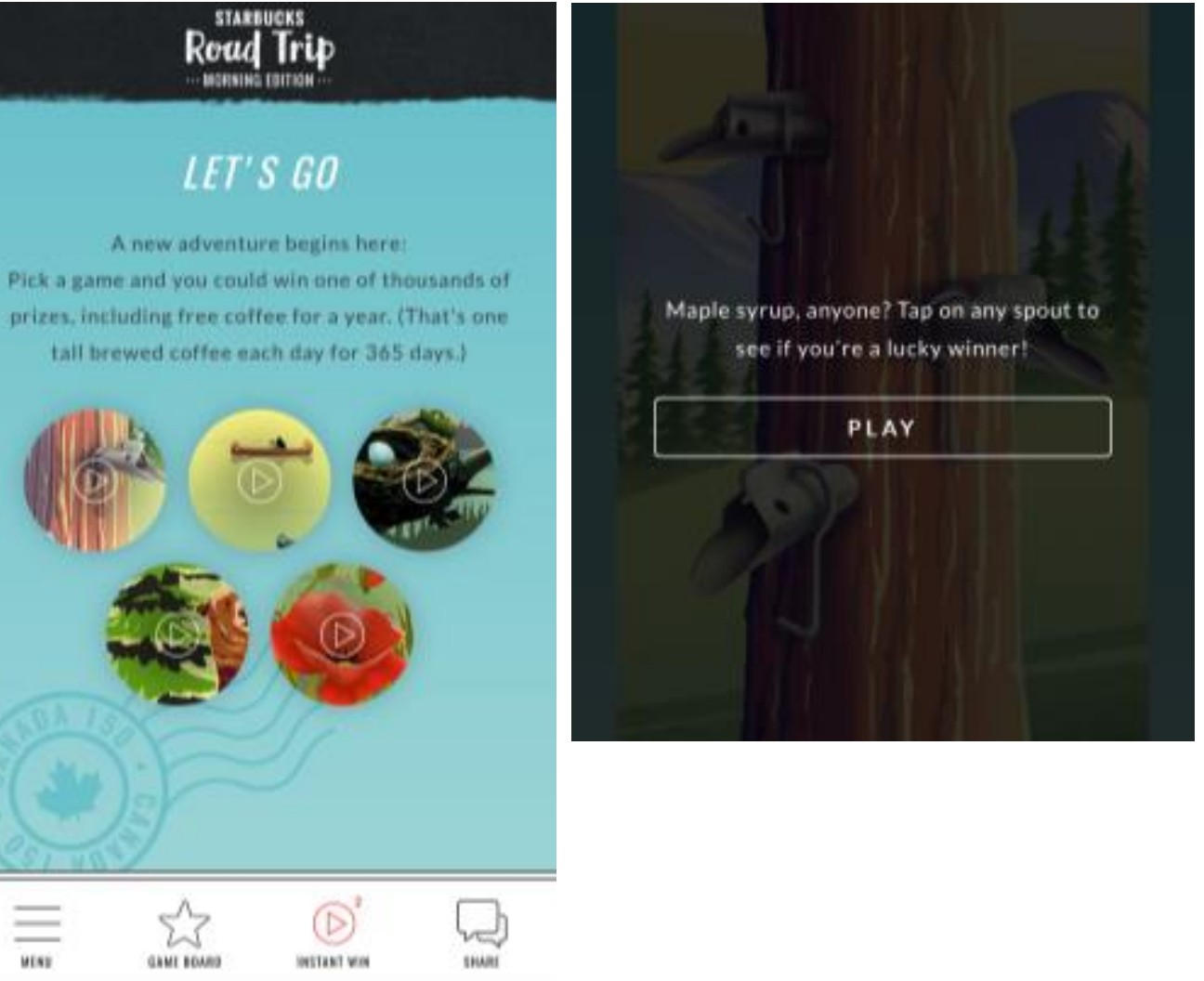


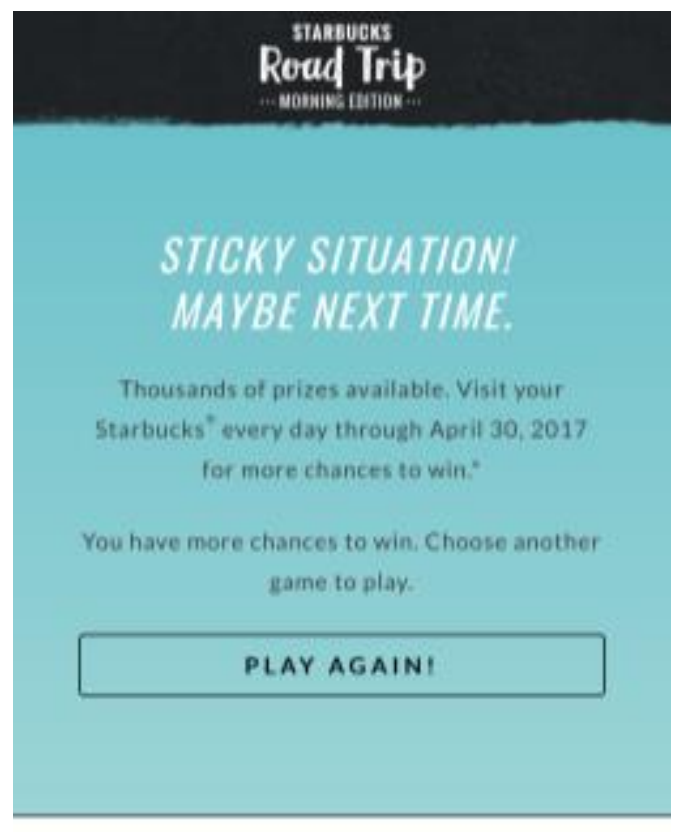

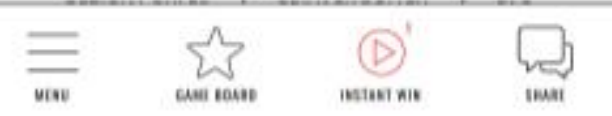

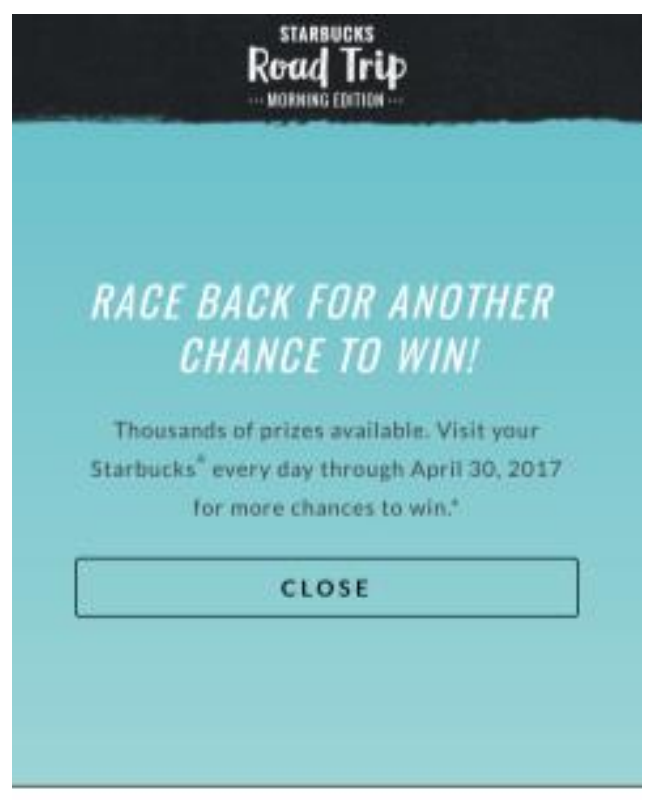

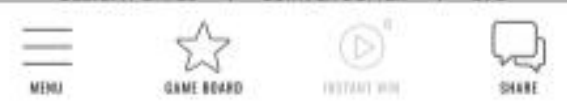

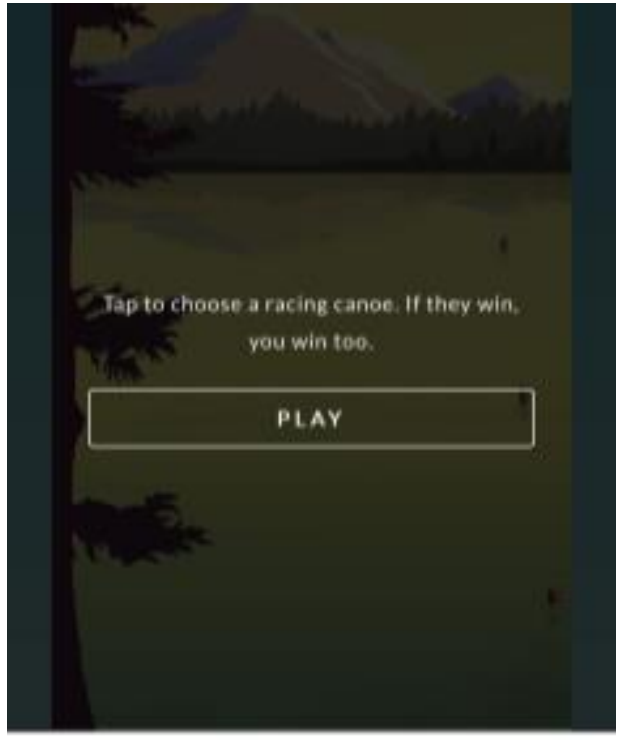

OHAcuchuiss | mervacypocicy | rap
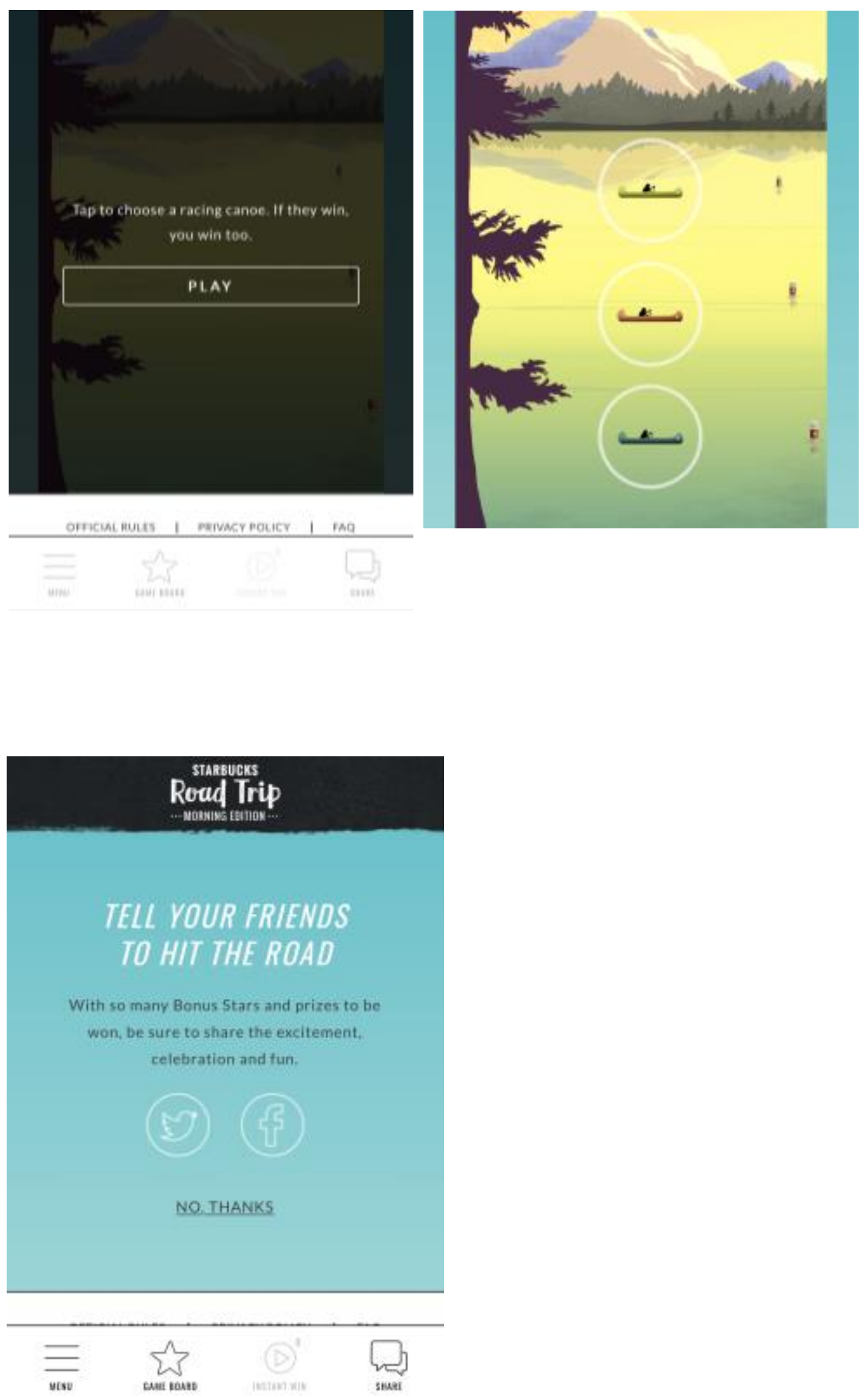


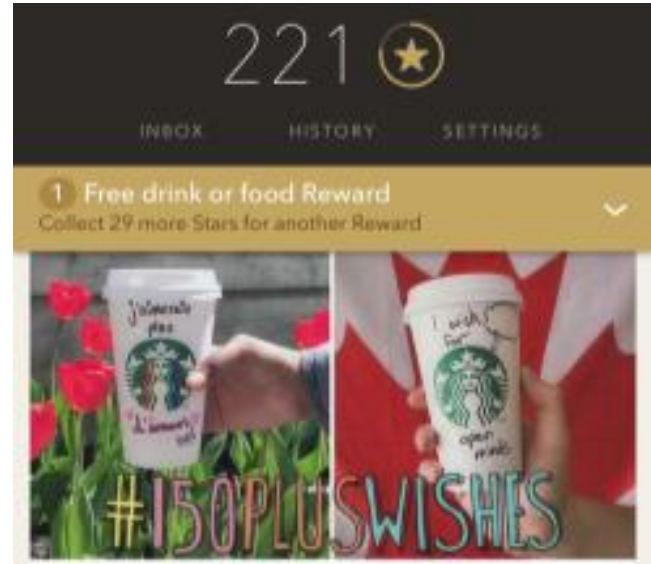

\#150PlusWishes for Canada's Future Write your wish on a Starbucks cup \& snap a photo. For each photo, we'll donate $\$ 1$ to charities that benefit youth.
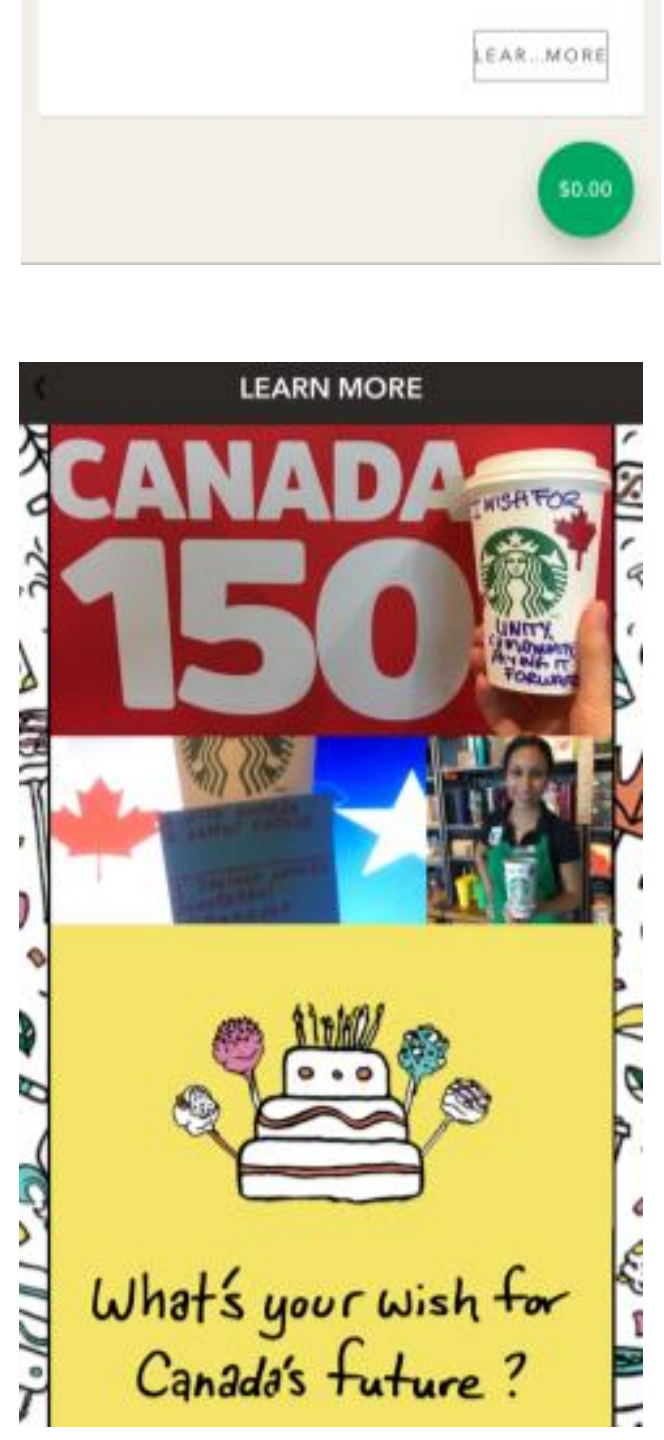
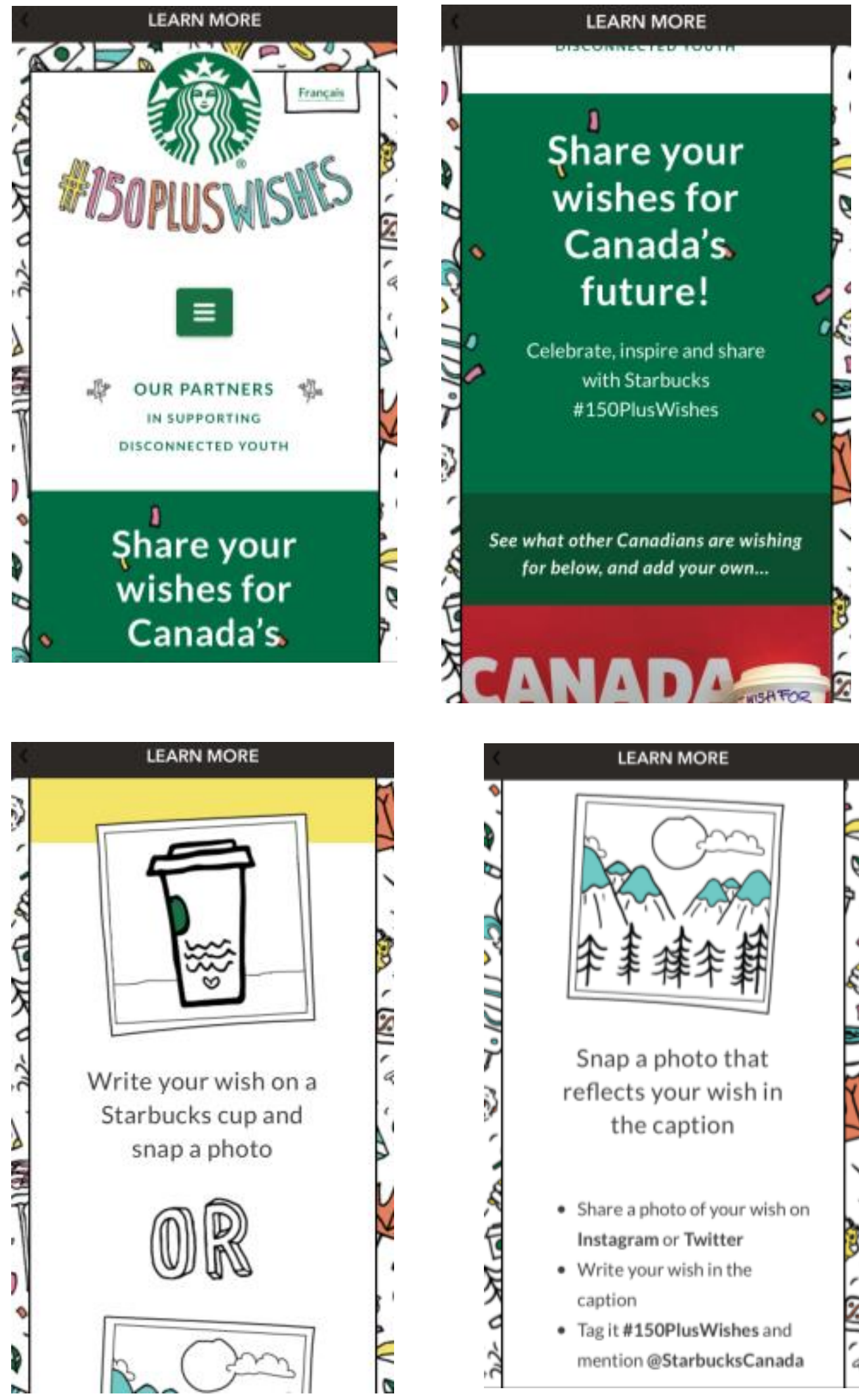


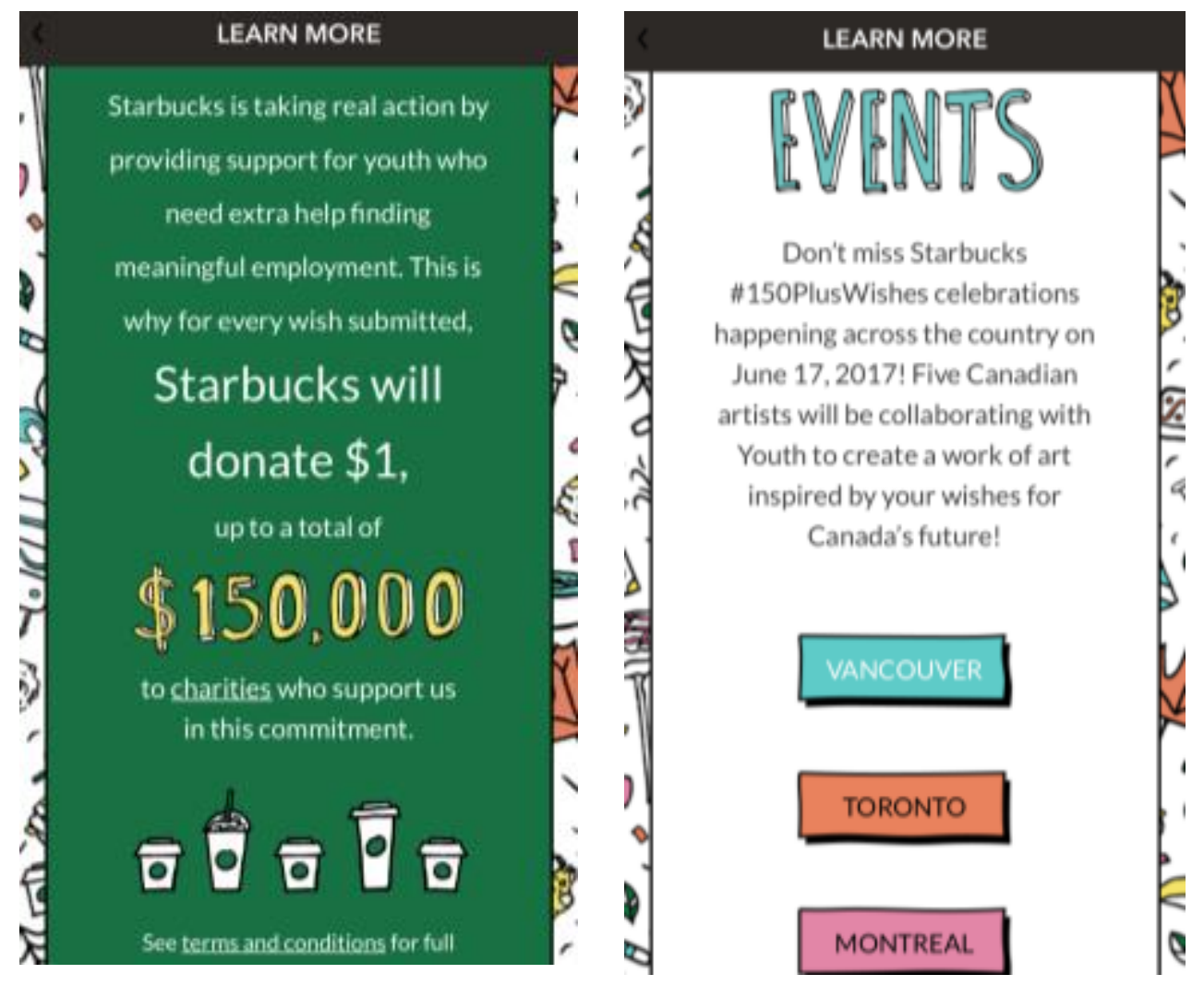


APPENDIX B: WEBSITE SCREENGRABS 
Appendix B: Website Screengrabs

STRBUCKS
REWARDS" Benefits Howto Earnstars Member Events The App Star Codes FAQs

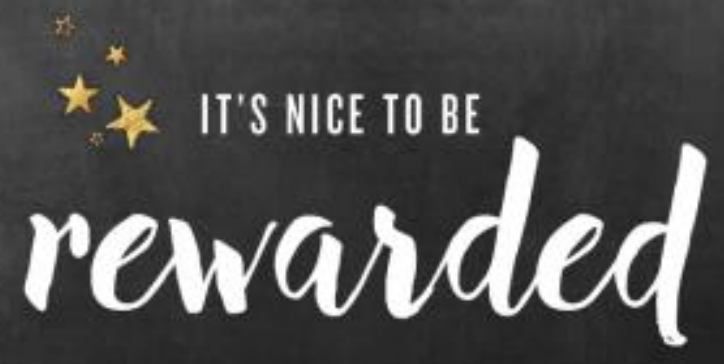

Make the most of your membership-pay with your phone, order ahead, earn free drinks and more

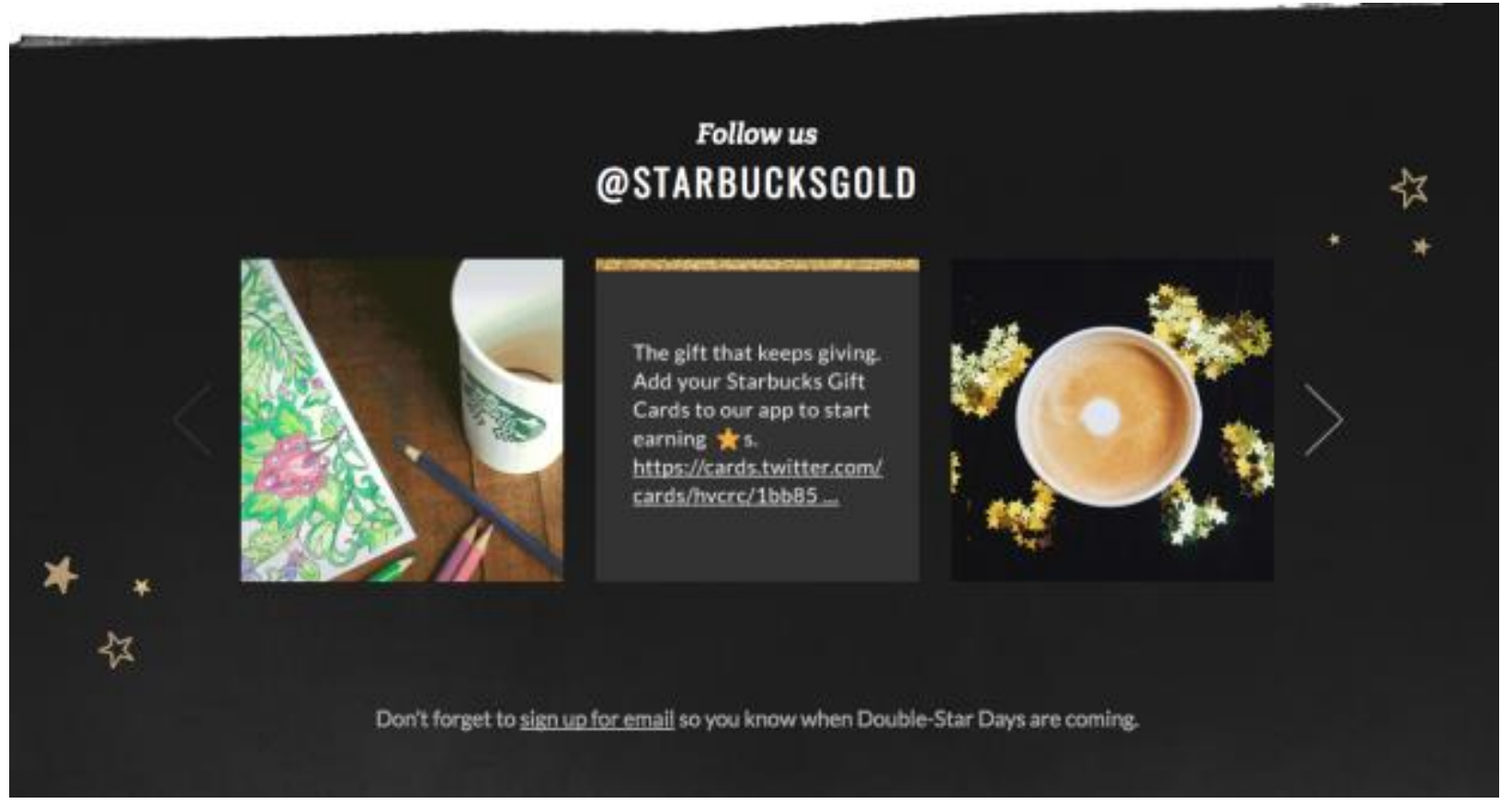




\section{Check out \\ MEMBER EVENTS}
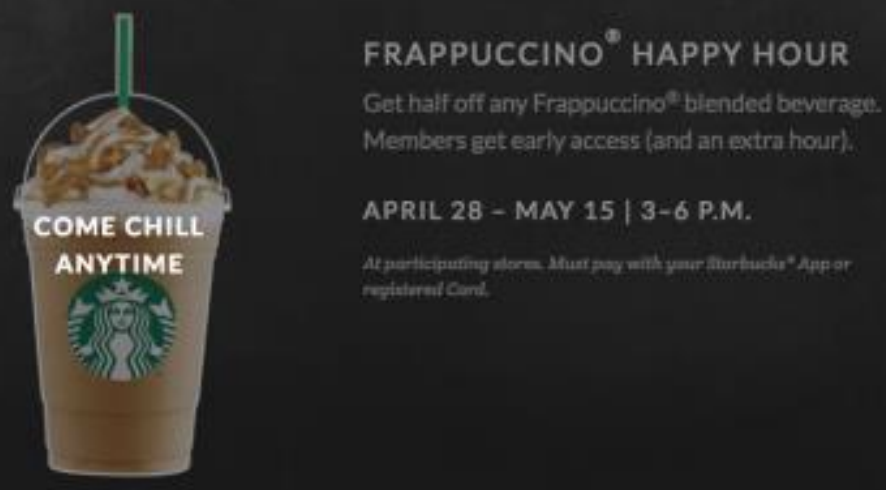

000000

Check out

\section{MEMBER EVENTS}

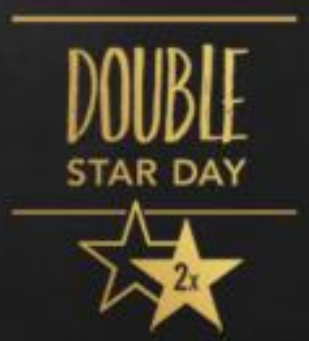

\section{DOUBLE-STAR DAY}

Don't miss out on Double Star Day - your day to earn 4 stars per $\$ 1$ spent (compared to 2 stars per 51). Make sure you are geted into email in your account to know when to participate.

\section{A Share}


gitranestracoses

STIRQUCK5

TREWARDS

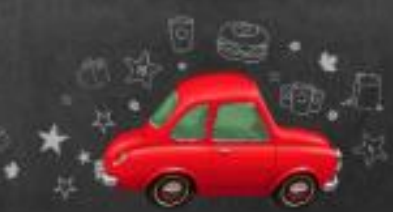

STARBUCKs Roud Trip.CA

MORHIKe EDIIION

Starbucks Rewards TWNC members swipe or scan to play Starbucks

\section{PLUS INSTANT STARBUCKS REWARDS ${ }^{\text {TM }}$ BENEFITS}

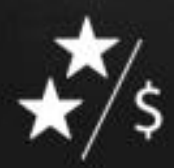

2 Stars per s1 Spent

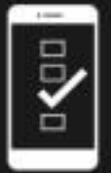

Order Ahead?

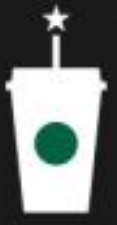

Free Birthday Reward

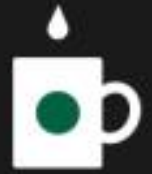

Free In-Store Refills

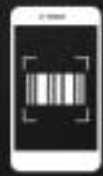

Pay by Phone

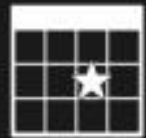

Member Events 8 Offers 


\section{AND MORE WITH GOLD STATUS:}

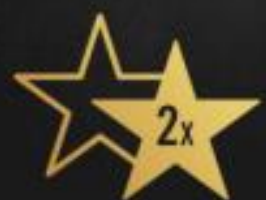

Monthly Double-Star Days

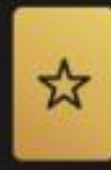

Personalized Gold Card

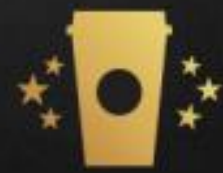

Star Reward Every 125 Stars

Some restrictions apply. Find out more below.

Like what you see? Join now >

Check out

\section{MEMBER EVENTS}

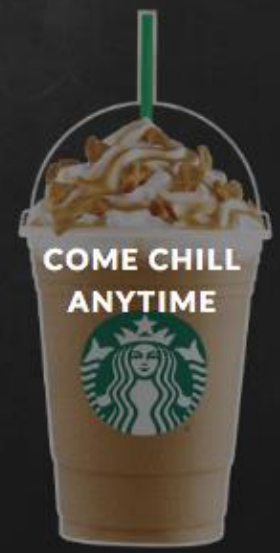

FRAPPUCCINO ${ }^{\circ}$ HAPPY HOUR

Get half off any Frappuccino ${ }^{\circ}$ blended beverage

Members get early access (and an extra hour).

APRIL 28 - MAY 15 | 3-6 P.M.

At participating stores. Must pay with your Starbuciks "App o: registered Card. 


\section{IN GROCERY STORES}

You can collect more Stars than ever from specially marked packaged coffee in grocery stores, and redeem Star Codes worth up to 20 Stars. Enter Star Code >

Earn 10 Stars on:

Starbucks ${ }^{\circledR}$ Roast and Ground Coffee (10-12 oz)

Earn 15 Stars on:

Starbucks ${ }^{\circledR}$ Roast and Ground Coffee (18-20 oz)

Earn 20 Stars on:

Starbucks ${ }^{\circledast}$ Roast and Ground Coffee (32-40 oz)

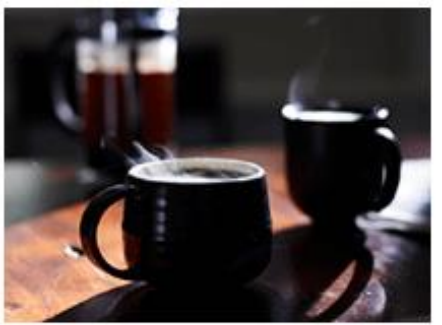

\section{IN EMAIL}

$\times$

Sign up for email so you don't miss out on over a billion Bonus Stars sent to Starbucks Rewards " members throughout the year. Subscribe now >

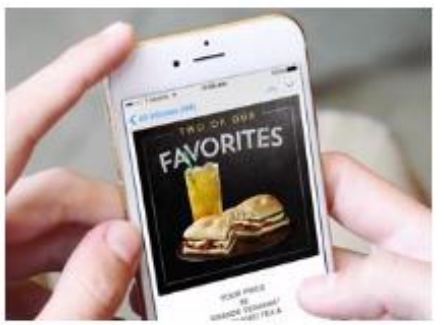

\section{AT STARBUCKS ${ }^{\circledast}$ \& TEAVANA ${ }^{\circledast}$ STORES}

$\times$

Earn 2 Stars for every dollar you spend in participating stores (including airports). Find a store >

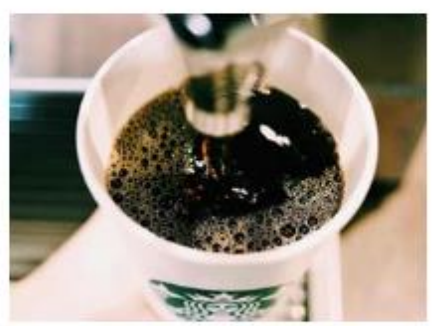

ON STARBUCKS.CA

Earn 2 Stars for every dollar you spend on coffee, tea, drinkware and more, just like you do in store. Shop now >

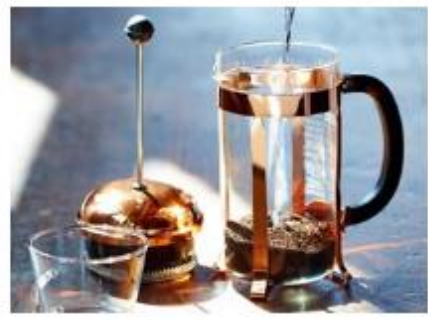


ON DOUBLE-STAR DAYS

Once a month, Gold members can earn 4 Stars per $\$ 1$ for all eligible purchases.
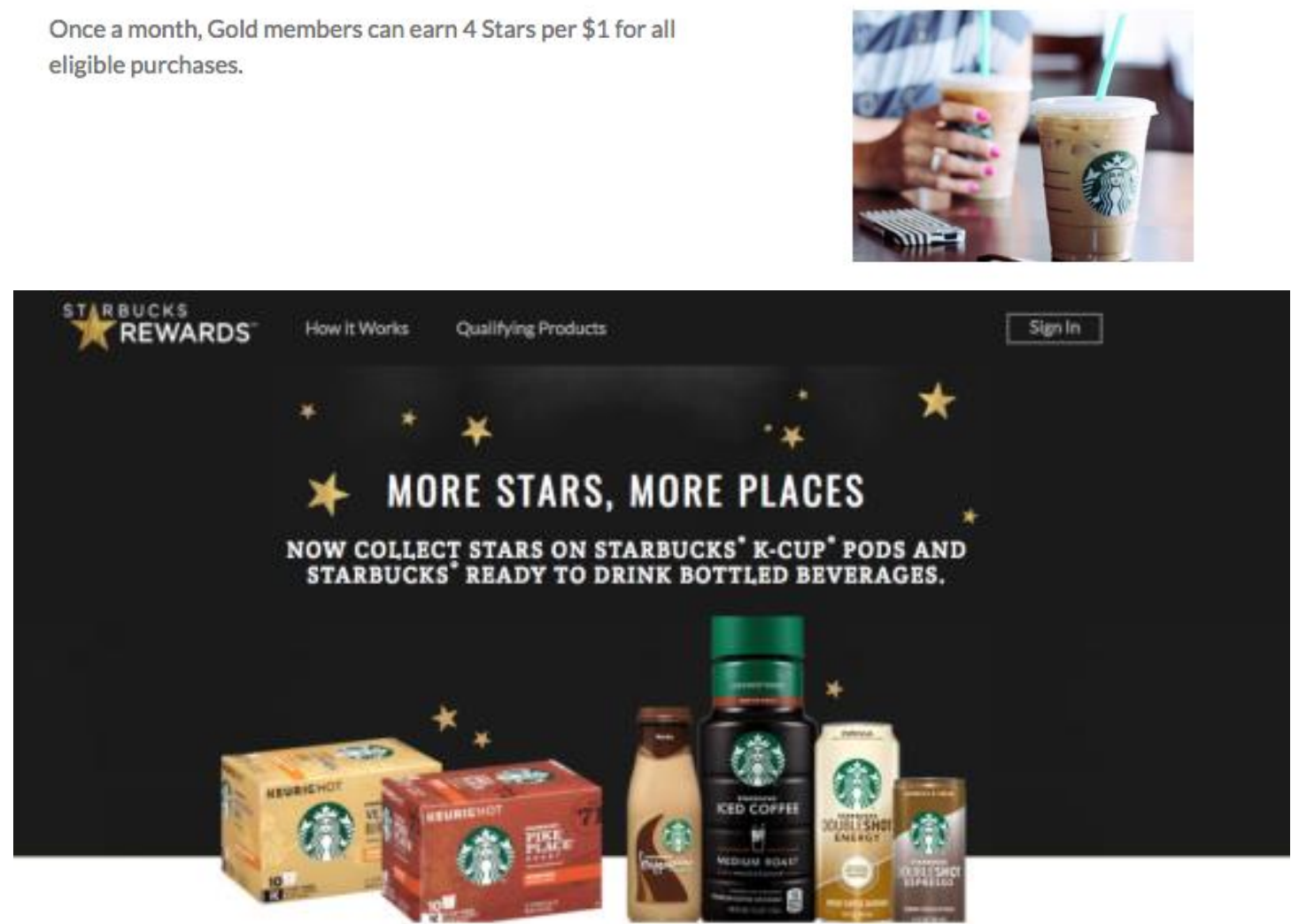

\section{HOW IT WORKS}

STEP 1: SHOP

Shap for your favorite qualifying Starbucks ${ }^{2}$ K-Cup ${ }^{8}$ pods or Ready to Drink products.
STEP 2: SIGN IN

Sign in ta your Starbucks Rewards" account or, if you are new to the program click on the Sigr Up Now button to register.
STEP 3: EARN

Earn Stars when you upload the neceipt for your purchase of qualifying products.

\section{Sign Up Now}

Welcome to Starbucks Rewards $\mathrm{m}$

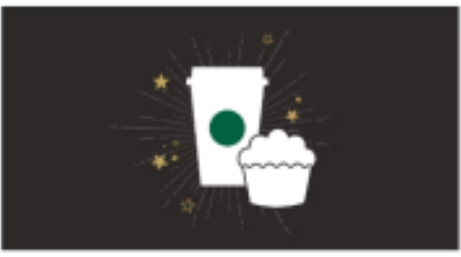

Collect 2 Stars for every $\$ 1$ vou spend an drinks. food muges and more

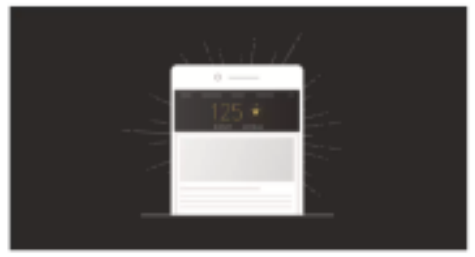

Gold members earn Rewards ewery 125 Stars, good for tree food and drirks.

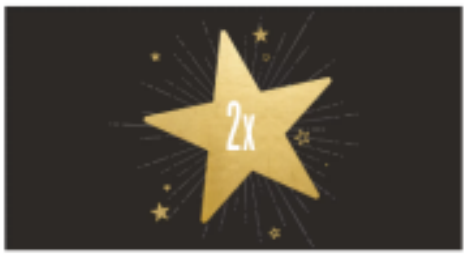

There are more ways to earn Stars, inchuding menthly Double-Star Days for Gold members.

DISMISS 


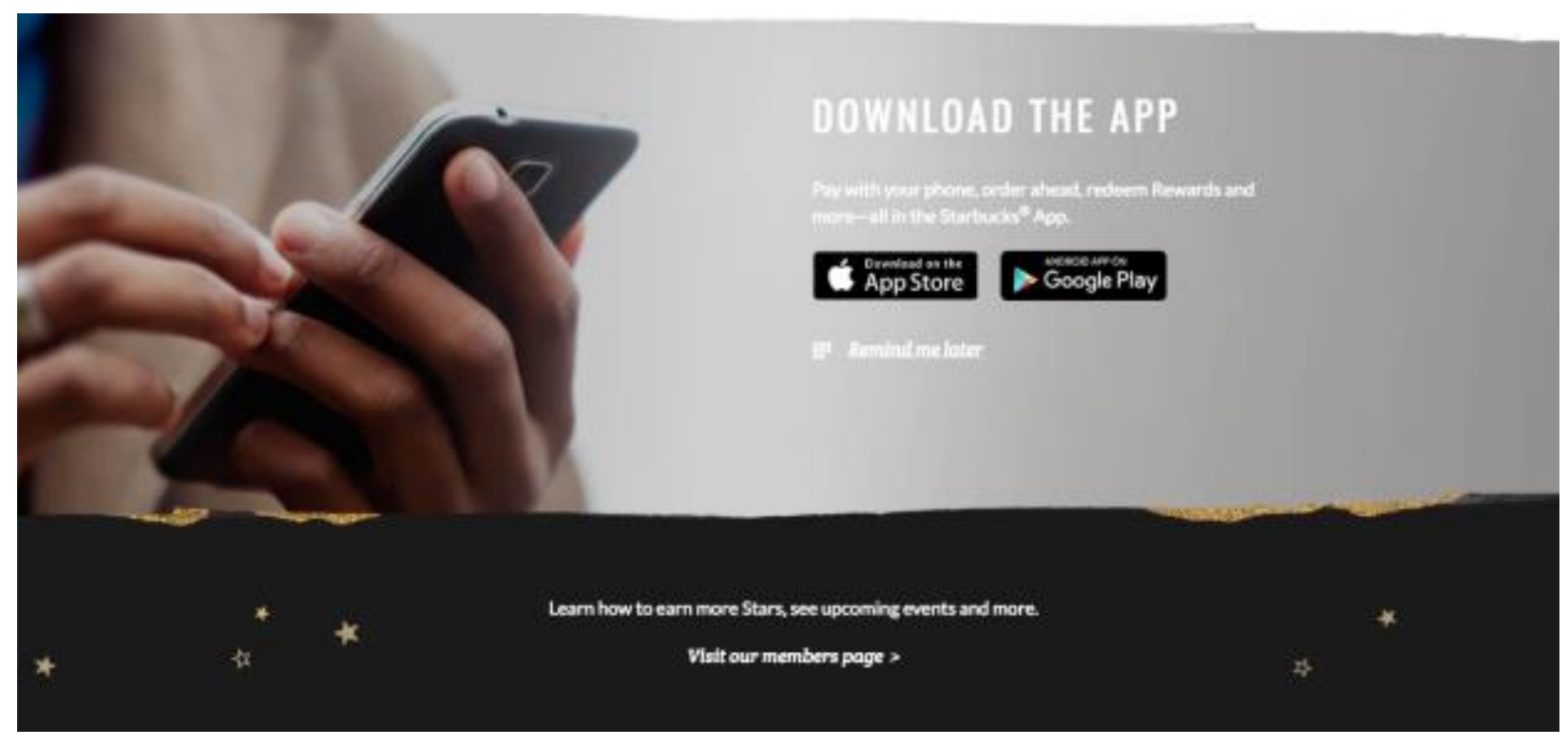

( $)$ Your Starbucks Card balance is under $\$ 10.00$. Relosd your Starbucks Card or set up auto-reload.

Stars and Rewards

My Cards

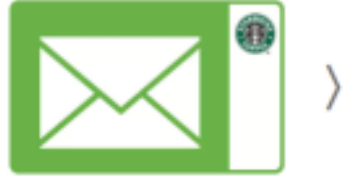

-

CAD $\$ 0.00$ sasespor C

\section{RELOAD CARD}

MANAGE 


\section{Campaign 1: Bingo}

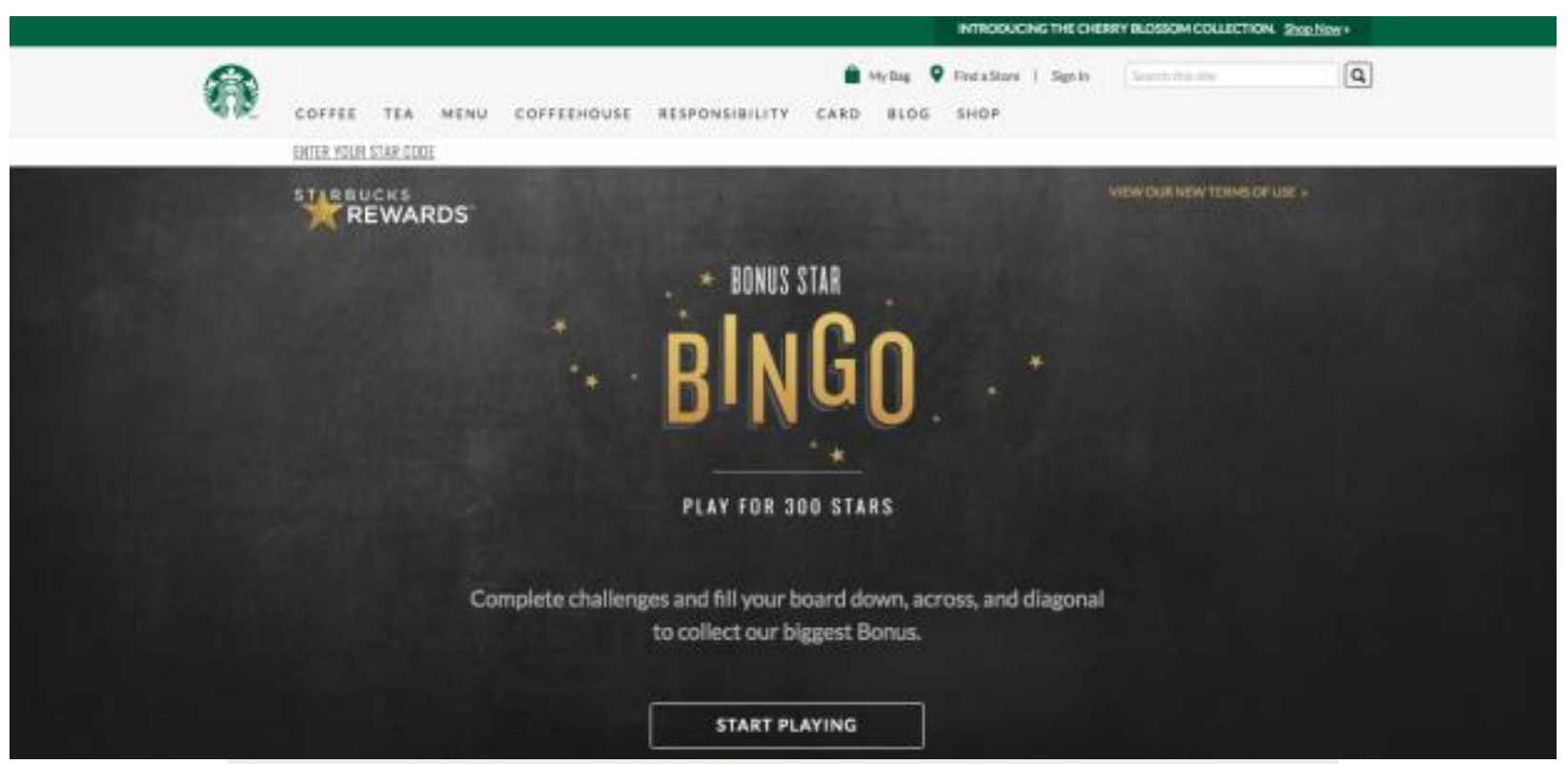

ST RBUCKS

REWARDS

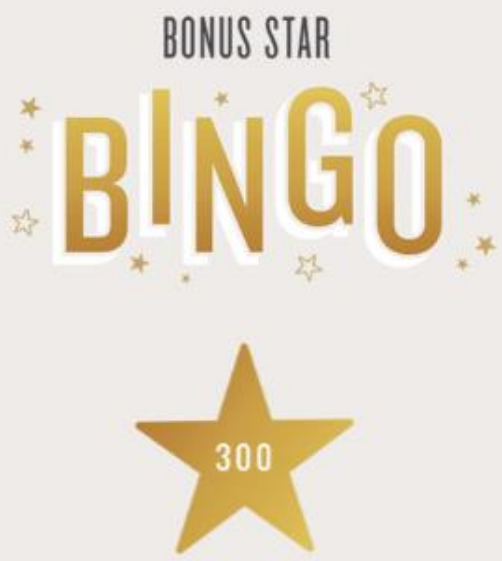

COLLECT STARS

Play to collect up to 300 Bonus Stars that add up to exclusive Gold Level benefits

like free drinks and food. 


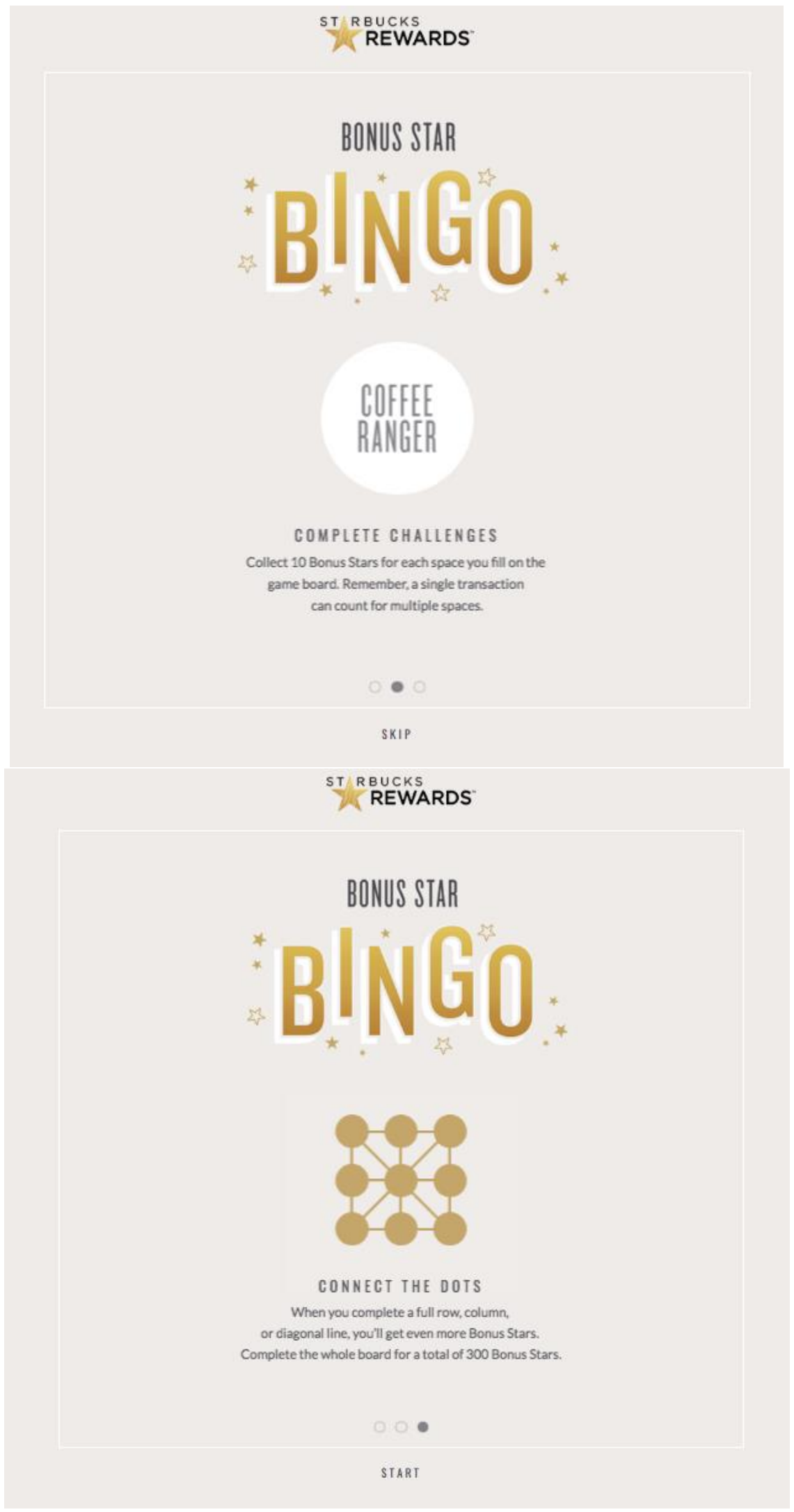




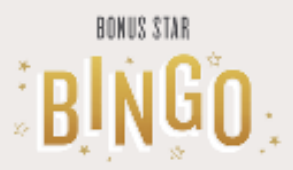

The more you play, the more you get.

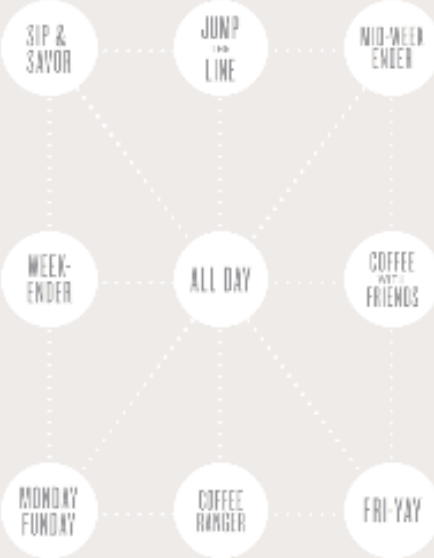

0

STARS COLECTE

OUT OF 300 
APPENDIX C: DESIGN ELEMENTS BREAKDOWN 
Appendix C: Design Elements Breakdown
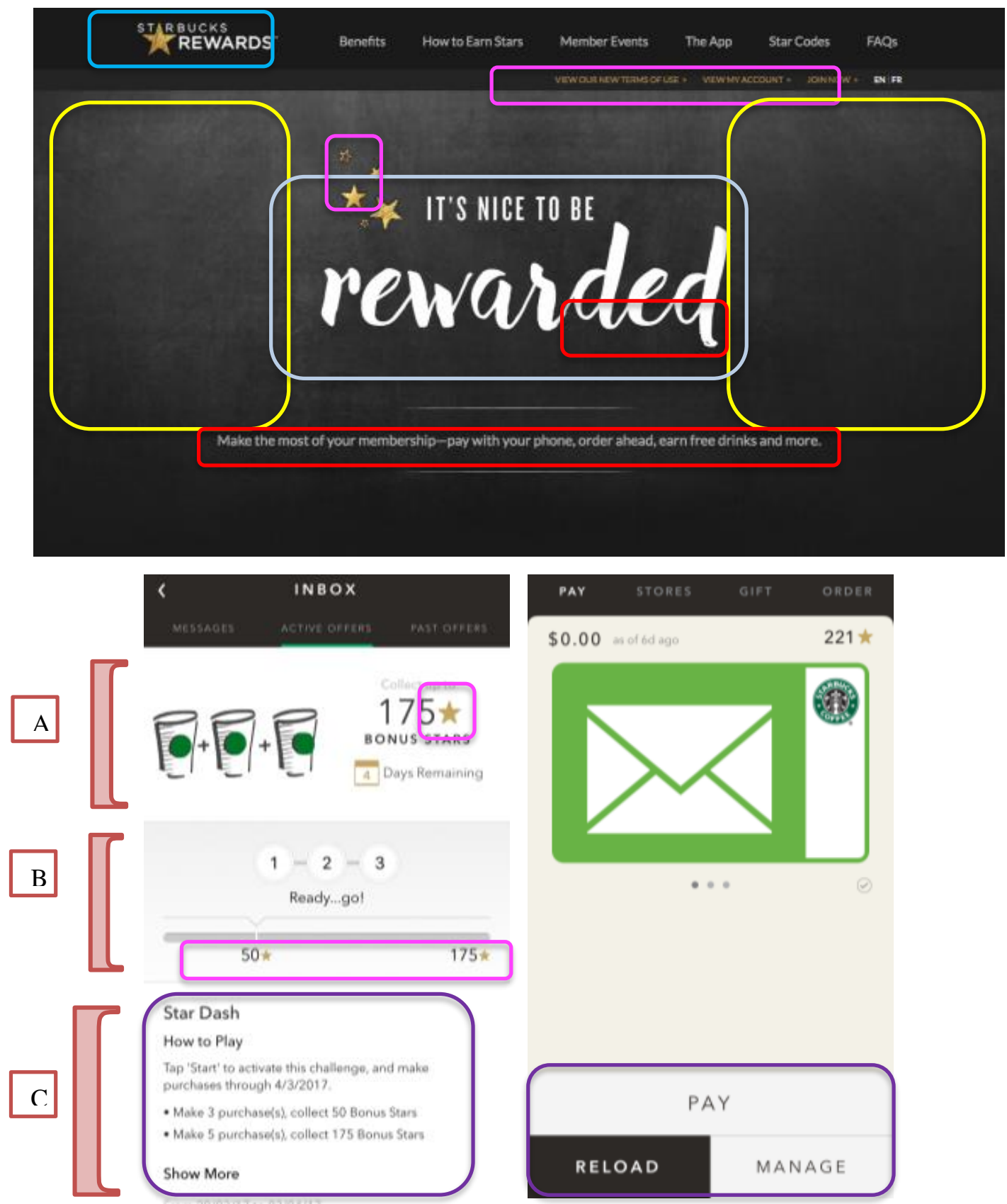

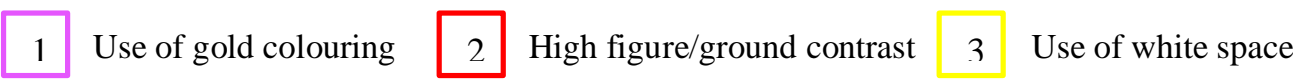

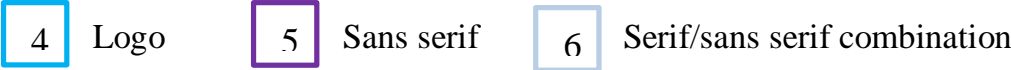

7 Rhetorical cluster breakdown 